\title{
Review of metering and gas measurements in high-volume shale gas wells
}

\author{
Yiming Zhang ${ }^{1} \cdot$ John Wang ${ }^{1}$
}

Received: 28 September 2021 / Accepted: 22 November 2021 / Published online: 14 December 2021

(c) The Author(s) 2021

\begin{abstract}
Coriolis, turbine, V-cone, and orifice meters have been used in measurement of gas production in shale wells. Flange-tapped concentric orifice meters are commonly used in measurement of shale gas production volumes due to their low cost, accuracy, and ease of maintenance compared to other types of meters. However, shale gas wells are producing at high flow rates, high pressure, and possibly gas compositions change, which might affect volumetric measurement accuracy that was developed for conventional gas wells. Thus, it is critical to investigate the metering and measurements technologies that are being applied in shale gas wells to further understand and improve the accuracy of gas volumetric measurements. This paper provides a comprehensive review and analysis of background information, design, measurement, and uncertainties associated with Coriolis meters, turbine meters, V-cone meters, and orifice meters. We also discussed the lessons learned through our field experiences in computing gas volumes using SCADA information in shale gas and conventional gas production.
\end{abstract}

Keywords Metering $\cdot$ Natural gas measurement $\cdot$ Shale gas

\section{Coriolis meter}

\section{Background information}

Coriolis mass flowmeters were introduced in the early 1980s for natural gas measurements and gained popularity in many gas flow applications in the past few decades due to the meters' improved accuracy and the capability of measuring the mass flow rate directly. The first application of Coriolis meters was proposed by $\mathrm{Li}$ and Lee in 1953 for liquid measurement, as the meter was proved successful for mass flow measurement of liquids with reliable accuracy prior to the application for natural gas measurements. However, due to the relatively low density of gas compared to liquids, the Coriolis effect induced by the gas mass flow was too small for the frequency phase change to be detected (about three orders of magnitude smaller than liquid). Kolahi et al. (1994) present a Coriolis meter prototype to measure the gas mass flow under normal conditions in their studies. They first studied whether the Coriolis effects can be amplified

John Wang

john.wang@psu.edu

1 The Pennsylvania State University, University Park, PA, USA by increasing the radial velocity of the tube. Since gas cannot be considered as incompressible fluid, the increase in the radial profile would not amplify the torsional oscillation unlimitedly and the Coriolis forces and torsional amplitude would eventually start to decrease. Their design of the prototype meter consisted of dual vibrating U-shaped tubes with tunable eigenfrequency designed for low density fluids measuring purposes. Their prototype results in an amplification of the torsional amplitude by a factor of 100, allowing the gas mass flow to be measured under normal conditions. Their works have opened up the possibilities for the Coriolis gas measurements applications.

Stewart (2002) performed experimental studies to assure the gas measurement quality using Coriolis meters with water calibration for validation. The measurements for water calibration were within $\pm 0.1 \%$ as expected, but only one of the meters falls within $\pm 0.5 \%$ of mass flow rates for air calibrations, with some of the meters displayed unexpected behavior. Grimley (2002) performed laboratory tests on Coriolis meters with natural gas using five Coriolis meters from three different manufacturers. The testing meters consist of the beam-mode dual bent-tube and shell-mode Coriolis meter designs. The natural gas flows were tested with a critical nozzle as the reference ranging from 180 to 1,000 psi. The gas flow measurements showed promises using

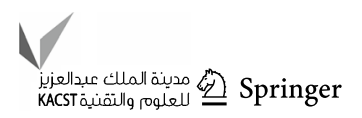


water calibration as the results fall within the uncertainty level of the reference meter. Wang and Baker (2014) provided a comprehensive review of Coriolis flow measurement technology over the past two decades across a wide range of fields and applications.

API first published methods to achieve custody transfer levels of accuracy when a Coriolis mass meter is used to measure liquid hydrocarbons (API 2002). American Gas Association (2001) also published Measurement of Natural Gas by Coriolis Meter, which is one of the most notable publications on Coriolis mass meters as their acceptance grows rapidly.

\section{Design}

Coriolis mass meter, Fig. 1, directly measures the mass flow rate of a fluid by vibrating a fluid-conveying tube at resonance. Coriolis meters can be categorized into rotary or vibratory types, with rotary types are more commonly used for bulk solid applications, whereas the vibratory types are designed for fluid measurement applications. Common configurations include dual or single U-shaped, horseshoeshaped, tennis-racket-shaped, or straight flow tubes with inlet on one side and outlet on the other as shown in Fig. 2. Dual-tube meters with a deep U shape configuration have the highest sensitivity to flow and the lowest pressure drop at a given accuracy, providing the advantage of having the widest range of flowrates. The dual-tube deep-U meter designs are optimal for low-mass-flow applications such as gases and high-viscosity liquids (O'banion, 2013). The two U-shaped flow tubes spilt the flow entering from the pipeline by the inlet manifold and rejoin at an outlet manifold then continue down the pipeline. However, the dual-tube designs require flow splitters that are prone to plugging, whereas the single tube designs offer a better solution in applications with such fluids. For single tube designs, the tube length increases dramatically as they would require more spaces and also results

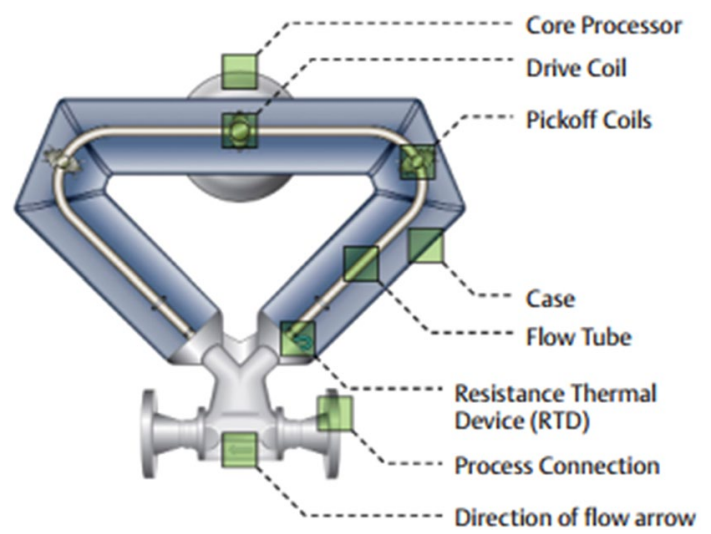

Fig. 1 Coriolis mass meter (Stappert 2013) a

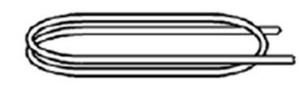

b

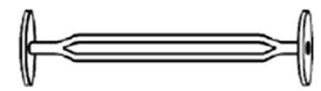

c

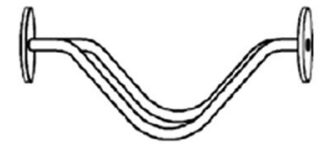

d

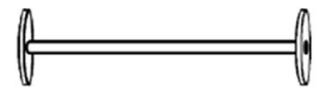

e
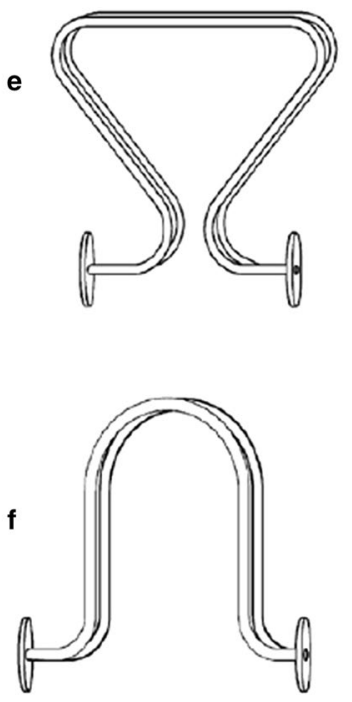

Fig. 2 Geometries of various Coriolis mass flowmeters (Anklin et al. 2006), a bended single tube, $\mathbf{b}$ dual straight tubes, $\mathbf{c}$ V-shaped bended twin tubes, $\mathbf{d}$ single straight tube, e horseshoe-shaped twin tubes, $\mathbf{f}$ curved twin-tubes

in increased pressure loss due to the pipe length. Every commercially available Coriolis mass meters all have an electromagnetic drive system consisting of a magnet and a coil causes the tube to vibrate toward and away from each other at their resonant frequency. This frequency is determined by the tubes' stiffness and their mass.

A Coriolis mass meter typically consists of two main components with the primary element being electromagnetic sensors (pickoff sensors) and a secondary unit of a driver (transmitter). At zero flow, both the inlet and outlet sinusoidal waves are in phase with each other. Under flowing conditions, when an oscillating excitation force is applied to the tube causing it to vibrate, the fluid flowing through the tube will induce a rotation or twist to the tube due to the Coriolis Effect acting in the opposite direction on either side of the applied force. Working principle of a Coriolis mass meter is presented in Fig. 3. The amount of

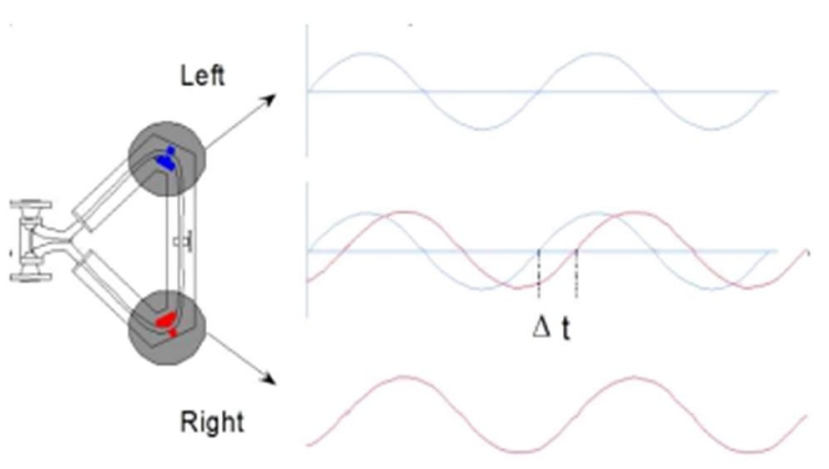

Fig. 3 Coriolis sensing/pickoff signals (Stappert 2013) 
twist creates the phase difference ( $d t$, time lag) measured by the transmitter between the pickoff sensors on the inlet and outlet sides which directly correlates with the mass flow through the tube.

Coriolis mass meters are expensive in terms of capital costs compared to other types of meters, and their price increases rapidly as the size of the meter goes up. The meter unit's weight also goes up significantly with size. However, since this type of meters does not require flow conditioners along with their low maintenance and high reliability, it can be advantageous in terms of life cycle costs. In a simple cost-analysis study of comparison between a small Coriolis meter and a DP/Orifice meter setup, O'banion demonstrates the long-term cost for the small Coriolis mass meter is about $55 \%-76 \%$ of a DP/Orifice meter over 10 years, with the capital cost of the Coriolis mass meter at four to seven times of the latter (O'banion, 2013).

Coriolis mass meters are limited in terms of range of sizes as well as the configuration of tubes, which may not be suitable for measuring large mass flow rate without resulting in excessive pressure drop. Each meter size and type have a pressure drop characteristic curve that is prepared by the manufacturers as illustrated in Fig. 4. The curve shows the tradeoff between pressure drop and flow accuracy and the user must accommodate for the selection of a specific Coriolis mass meter to balance pressure drop and accuracy.

The Tek-Cor 1100A series Coriolis flow meter consists of line sizes ranging from 0.5 to 6 inches for gas measurements with accuracy up to $\pm 0.5 \%$ (based on water measurement under standard conditions), density accuracy up to $\pm 0.001 \mathrm{~g} / \mathrm{cm}^{3}$, and repeatability up to $\pm 0.25 \%$. The sensor types for this model series include standard (dual U-tubes), U-tube, nano, super bend, straight tube, and dual path. It is recommended to have velocity less than one-third of the sound velocity for gas measurement as high-speed gas flow

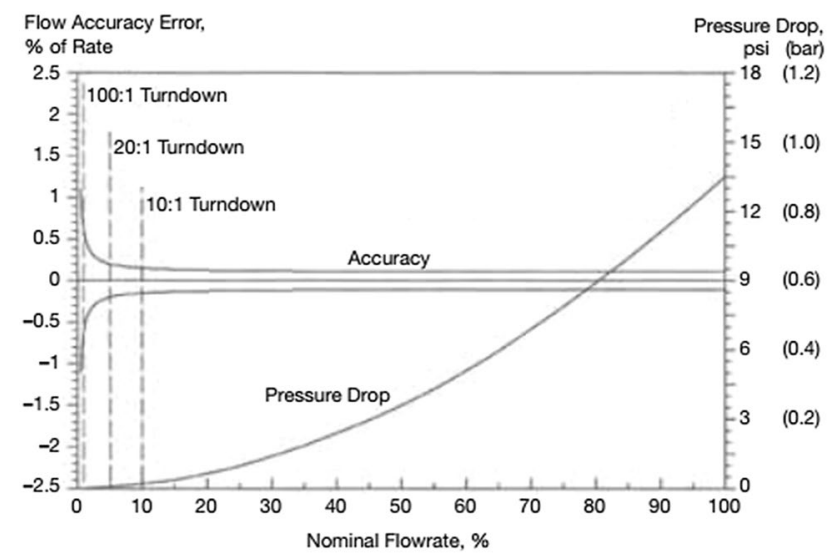

Fig. 4 Coriolis mass meter pressure drop (O’banion 2013) introduces loud noise that can interfere with the accuracy of the measurements (Tek-Trol 2021).

The Micro-Bend Coriolis mass flowmeter ALCM-MB from SmartMeasurement consists of line sizes ranging from 0.5 to 8 inch for gas measurements with accuracy up to $\pm 0.5 \%$ (based on water measurement under standard conditions), density accuracy up to $\pm 0.001 \mathrm{~g} / \mathrm{cm} 3$, and repeatability up to $0.075 \%$. It employs an unique U-tube design with a significantly smaller radius compare to the traditional U-tube type Coriolis meters as the compact design can significantly reduce pressure differential. The construction of the meter is typically built with 304 stainless steel (SmartMeasurement 2019).

Micro Motion has several series of Coriolis Meter includes ELITE, F-Series, and T-Series as they are capable for gas measurements. The ELITE series consists of line sizes ranging from $1 / 12$ to 16 inch for gas measurements with accuracy up to $\pm 0.35 \%$ and repeatability up to $\pm 0.20 \%$. The F-Series consists of line sizes ranging from 0.25 to 4 inch for gas measurements with accuracy up to $\pm 0.50 \%$ and repeatability up to $\pm 0.25 \%$. The T-Series consists of line sizes ranging from 0.25 to 2 inch for gas measurements with accuracy up to $\pm 0.50 \%$ and repeatability up to $\pm 0.05 \%$ (Emerson 2021b).

\section{Measurement}

A practical implementation for the curved tube Coriolis meter (Fig. 2f) operating equation is shown in Eq. 1 (AGA No.11, 2001). Equations and methods for the conversion of mass to base volume are documented in AGA Report Number 11 and AGA Report Number 8, Compressibility Factors for Natural Gas and Other Hydrocarbon Gases. Equation 2 shows the relationship between direct mass flow measurement and volumetric flow at base conditions. This equation is developed based on the conservation of mass and requires the knowledge of the gas composition to calculate base density using an equation of state.

$$
\begin{aligned}
& q_{\mathrm{m}}=\mathrm{FCF} \times F_{\mathrm{T}} \times F_{\mathrm{P}} \times\left(\Delta t-\Delta t_{0}\right) \\
& F_{\mathrm{T}}=1-K_{\mathrm{T}} T \\
& F_{\mathrm{P}}=1+K_{\mathrm{P}} P \\
& q_{\mathrm{b}}=\frac{q_{\mathrm{m}}}{\frac{P_{\mathrm{b}} \times M_{\mathrm{r}}}{Z_{\mathrm{b}} \times R \times T_{\mathrm{b}}}}
\end{aligned}
$$

where: $q_{\mathrm{b}}$-Volumetric flow rate at base conditions, in cubic feet per hour; $q_{\mathrm{m}}$-Mass flow measured by the Coriolis mass meter, in pounds per hour; $q_{\mathrm{f}-\text { Volumetric flow rate at line }}$ conditions, in cubic feet per hour; FCF-Flow calibration 
factor; $F_{\mathrm{T}}$-Temperature compensation; $K_{\mathrm{T}}$-Temperature coefficient (directly related to changing Young's modulus vs. temperature); $F_{\mathrm{P}}$-Pressure compensation; $K_{\mathrm{P}}$-Pressure coefficient; $M_{\mathrm{r}}$-Gas molar mass at base conditions, in pound mass per pound mole; $P$-Operating fluid pressure, in psi; $P_{\mathrm{b}}$-Absolute pressure of the gas at base conditions, in psia; $P_{\mathrm{f}}$-Pressure of the gas at line conditions, in psi; $R$ Universal gas constant; $\Delta t$-Phase induced by the flowing gas; $\Delta t_{0}$-Residual phase at zero flow; $T$-Primary element flow tube temperature, in degree Fahrenheit; $T_{\mathrm{b}}$-Absolute temperature of the gas at base conditions, in degree Rankine; $T_{\mathrm{f}}$-Temperature of the gas at line conditions, in degree Rankine; $Z_{\mathrm{b}}$-Fluid compressibility at base conditions; $Z_{\mathrm{f}}-$ Fluid compressibility at line conditions.

Density is determined at no flow conditions by measuring the natural frequency of the tube containing the particular fluid. Electromagnetic sensors excite the measuring tubes at their resonance frequency and any changes in mass (thus the density) of the oscillating system (measuring tubes and fluid) will result in a change of the resonance frequency. The resonance frequency is directly related to the density of the fluid inside the tubes. Typically, a microprocessor flow computer will utilize this relationship in order to obtain the density signal of the fluid. Some manufacturers have dedicated gas density/specific gravity unit (SGU) devices for gas density measurements because changes in density are too small to resolve with Coriolis technology. AGA Report No.8, Compressibility Factors of Natural Gas and Other Related Hydrocarbon Gases can also be used as a reference in calculating the density of the flowing gas.

The temperature of the measuring tubes is determined in order to calculate the compensation factor due to any temperature effects. The flow computer utilizes this signal, which corresponds to the product temperature, along with the mass flow determination and density of the fluid to determine the volumetric flow accurately. Most Coriolis mass meters are equipped with a temperature sensor to compensate for any slight changes in the tube's stiffness (Young's modulus) resulted by the temperature.

Since it is not quite common in the industry to use mass measurement for custody transfers, with volume being equal to mass flow divided by density, a flow computer can convert the Coriolis mass meters' outputs into volume. The accuracy of volumetric flow rates measured by Coriolis mass meters would be dependent on the accuracy of both the density measurement as well as the mass measurement.

\section{Uncertainties}

Coriolis mass meters are well known for their phenomenal accuracy, $\pm 0.1 \%$ for liquid mass and volume measurement accuracy, $\pm 0.5 \%$ for gas's mass measurement accuracy, and error range of \pm 0.002 to $\pm 0.0005 \mathrm{~g} / \mathrm{cm}^{3}$ for density measurement accuracy. They are also independent of flow profile, fluid composition, and material constants such as heat conductivity, heat capacity, and viscosity.

Such a single device can provide multivariable outputs, there are fewer instruments to specify, install, calibrate, and maintain, which makes Coriolis mass meters ideal for relatively low flow rate measurement ranging from 2.8 to $400 \mathrm{lb} / \mathrm{min}$ (or 64 to $9500 \mathrm{SCFM}$ ) for gas measurements. Coriolis mass meters can measure the flow rate accurately over a 100:1 turndown ratio and density in the range of 0 to $5 \mathrm{~g} / \mathrm{cm}^{3}$. This type of mass meters is even suitable for liquid flow measurements with a small amount of gas, but it is ideal for single phase measurement. Coriolis mass meters are also bidirectional, which can handle flow in either direction with no adjustments Every Coriolis mass meter should be calibrated accordingly to the measuring fluid types prior to use. The uncertainty of the calibration is primarily affected by meter linearity, repeatability, and calibration reference uncertainty. Most manufacturers state an uncertainty of $\pm 0.5 \%$ of mass flow rate which includes all of these effects. Most Coriolis mass meters operate on signal levels below 60 microseconds and can even detect $\mathrm{d} t$ as small as a few nanoseconds.

Since the amplitude of the oscillation from the Coriolis meters may be only a few tens of micrometers, the measurement can be very sensitive to even small disturbances. To minimize measurement errors from such effects, Coriolis meters must be balanced accurately. The symmetry of dualtube designs offers the best performance for the decoupling of the meters from the external disturbances with its robust balancing system. For the single tube meters however, it is quite challenging and difficult to find a balancing mechanism that allows the meter to measure precisely under various external conditions and the changing in fluid densities.

Koudal et al. (1998) in their studies have shown that the pulsation effects are not only crucial at the frequency of pulsation but also at frequency differences between the pulsation and the Coriolis effect frequency. Coriolis meters with high working frequencies are much less sensitive these external disturbances as the differences between the frequencies are high, typically above $200 \mathrm{~Hz}$. Cheesewright et al. (2000) investigated the response of Coriolis meters to a variety of external disturbances. Their studies showed the Coriolis calibration accuracy is not affected by inlet flow conditions, such as upstream swirl effects, asymmetric flow profile, or increased turbulence. But for meter external disturbances, the tested Coriolis meters resulted in severe calibration errors at the presence of flow pulsations and/or mechanical vibrations at the Coriolis frequency. However, these errors are predominately due to failure of the outdated phase measurement algorithm, they can be overcome by using 
high performance filtering techniques, especially with the improved designs of Coriolis meters to minimize the effect of external influences. The disturbances at frequencies close to the meter drive frequency will produce measurement errors.

Bobovnik et al. (2005) developed a fully coupled, partitioned, numerical model using finite volume method (FVM) for the turbulent fluid flow and finite element method (FEM) for the deformable shell structure for a straight-tube Coriolis meter. The FVM/FEM numerical model was validated with the solutions of the Euler beam one-dimensional flow model and the Flügge shell and potential flow model. Mole et al. (2008) improved upon the iterative coupling method by introducing forced vibration simulation into the model. The effects of Reynolds number on a straight flow tube were analyzed using this improved model and results agreed well with weight vector analysis conducted by Kutin et al. (2006). Bobovnik et al. used this iterative coupling method to study the effects of disturbed velocity profiles due to installation effects for a short straight tube full-bore design (2013) and single and twin tube (2015).

Pope and Wright (2014) conducted experiments to analyze the performance of Coriolis meters in transient gas flow using nitrogen and helium gases through two Coriolis meters at the National Institute of Standards and Technology's Transient Flow Facility. Both meters were capable of measuring the totalized mass from the transient flows within $1.0 \%$.

For natural gas measurements, Anklin et al. (2006) described due to the low density of the flowing gas, Coriolis mass meters for gas applications are often used near the lower end of their rangeability. The performance of the gas mass measurement will be increased with higher mass flow. The turndown of the mass meter can also be improved by increasing the inline pressure of the flowing gas, which is why it is recommended to have the Coriolis meter be installed at the high-pressure side. The preferred orientation of installation for gas applications is to install the meter vertically with the flow direction upwards. This set-up allows the entrained solids to sink downwards as the gases flowing upwards when the medium is not flowing; this also protects the meter and tubes from solids build up as well as draining the meter tubes completely.

Anklin et al. (2006) describe the effects of corrosion and erosion to the Coriolis metering system, as these effects will diminish the wall thickness thus change the stiffness of the tube. The results can lead to inaccuracy in mass measurements and safety issues. For strongly abrasive fluids, erosion can be reduced by keeping the flow velocity low. The effects of erosion are also the smallest for straight single tube meters. There are built-in diagnostic implementations for Coriolis meters available for detecting corrosion or erosion.

\section{Turbine meter}

\section{Background information}

Turbine meter measures volumetric flow rate by counting the revolutions of a rotor inside the meter as the angular velocity of the rotor is proportional to the gas flow velocity. The idea of such a meter can be dated all the way back to the ancient Rome, as Roman architect Vitruvius developed one of the first odometer primary used as a surveying instrument consisted of a wheel of known circumference that dropped a pebble into a container on every rotation. Robert Hook utilized the mechanics of a small windmill in 1681 to measure air velocity based on the windmill's rotations and eventually implemented as a distance meter for naval ships.

The first modern Turbine meters were developed in 1938 in the United States, consisting of a helically bladed rotor and simple bearings as they became quite popular for fuel flow measurement in airborne applications. In 1961, Potter developed and patented his version of Turbine meter. As Potter profiles the hub of the rotor, the observations of the pressure balance across the rotor held it against the axial drag forces rather than the thrust bearings, which led to the implementation of his meter to allow the rotor to run on a single journal bearing.

\section{Design}

Turbine meter converts the kinetic energy of the flowing fluid into rotational energy. For an ideal turbine meter, barring any drag forces, the rotational speed of the rotor inside the meter would be directly proportional to the volumetric flow rate of the measuring fluid. In practice however, the drag forces from the system can slightly retard the rotation and lead to a nonlinearity relationship for the measuring mechanisms. These drag forces include frictional drag on the blades, the hub, the faces of the rotor, and the tip of the blades; bearing drag; magnetic drag due to the means by which the rotation is measured (Baker 1991).

A typical Turbine meter consists of either straight or helical blades and designed to create the minimum disturbance to the oncoming flow. The advantages of the helical blades are due to the relative angle of approach of the fluid on to the blades, whereas the straight blades will not allow a constant angle of attack, which lead to unnecessarily large incidence angles and introduce flow disturbance and

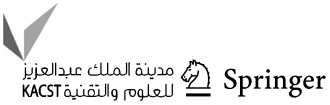


drag. The rotor spindle must be held centrally in the pipe in bearings, which are commonly used as flow straighteners as they reduce swirl due to conservation of angular momentum as the fluid redistributed into the annular passage past the blades. The rotation of the rotor is sensed most commonly by a change in the magnetic field around the sensor.

For a gas turbine meter, the most obviously differences in design are the large hub and comparatively small flow passage, allowing the fluid to impart as large a torque as possible on the rotor by moving the flow to the maximum radius and increasing the flow velocity. Figure 5 shows a schematic of axial-flow, single-rotor gas Turbine meter. The flowing gas entering the meter increases in velocity through the annular passage formed by the nose cone and the interior wall of the body. The movement of the gas over the angled rotor blades rotates the rotor, and the rotation is registered by either a mechanical or an electrical readout. Another type of gas Turbine meter, shown in Fig. 6, consists a dual-rotor design with a secondary rotor placed behind the primary rotor. The primary rotor still serves the same function as the single rotor system. The secondary rotor downstream from the main rotor typically operates at a lower speed than the main rotor in order to extend its service life and differentiate the measurements of the two rotors for validation purposes. Some of the dual-rotor designs also provide self-diagnostic and self-correction capabilities as the secondary rotor can provide measurement adjustments to improve the output error from the primary rotor.

The rotor material is typically made of Delrin or aluminum for sizes greater than six inch. Number of blades are typically 12 to 24 with the maximum pulse frequencies up to $3000 \mathrm{~Hz}$. The maximum pressure rating is up to 1450 psi, but these figures can vary significantly among manufacturers. It is quite common to include an electrical readout as well as a mechanical register especially for gas Turbine meters.

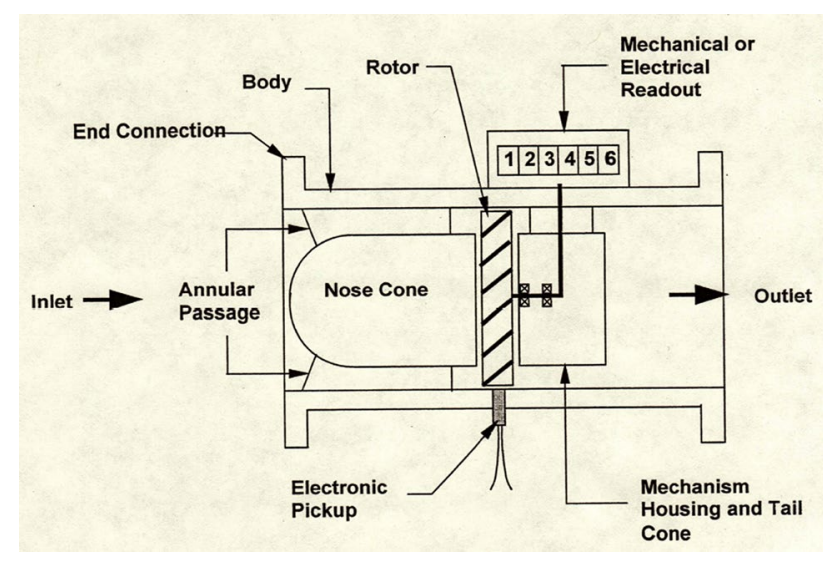

Fig. 5 Single rotor turbine meter, gas design (AGA 7 2006)

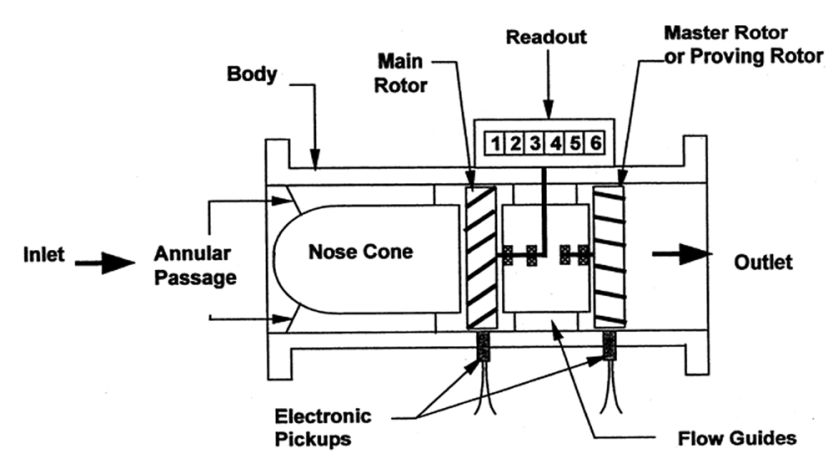

Fig. 6 Dual-rotor turbine meter with independent tandem separated by flow guides (AGA 7, 2006)

\section{Measurement}

Turbine meter typically registers gas volume continuously at flowing pressure and temperature conditions converted on the rotor revolutions counted mechanically or electrically. For measurement, the registered volume must be corrected to the specified base conditions using the following equations (AGA 7 2006).

$V_{\mathrm{b}}=V_{\mathrm{f}}\left(\frac{P_{\mathrm{f}}}{P_{\mathrm{b}}}\right)\left(\frac{T_{\mathrm{b}}}{T_{\mathrm{f}}}\right)\left(\frac{Z_{\mathrm{b}}}{Z_{\mathrm{f}}}\right)$

$Q_{\mathrm{f}}=\frac{V_{\mathrm{f}}}{t}$

$Q_{\mathrm{b}}=Q_{\mathrm{f}}\left(\frac{P_{\mathrm{f}}}{P_{\mathrm{b}}}\right)\left(\frac{T_{\mathrm{b}}}{T_{\mathrm{f}}}\right)\left(\frac{Z_{\mathrm{b}}}{Z_{\mathrm{f}}}\right)$

where $V_{\mathrm{b}}$-Volume at base conditions, in cubic feet; $V_{\mathrm{f}}$ Volume measured at flowing conditions during time interval $t$, in cubic feet; $Q_{\mathrm{b}}$-Volumetric flow rate at base conditions, in cubic feet per hour; $Q_{\mathrm{f}}$-Volumetric flow rate at flowing conditions, in cubic feet per hour; $P_{\mathrm{b}}$-Absolute pressure of the gas at base conditions, in psia; $P_{\mathrm{f}}$-Pressure of the gas at flowing conditions, in psi; $t$-Time, in hour; $T_{\mathrm{b}}$-Absolute temperature of the gas at base conditions, in degree Rankine; $T_{\mathrm{f}}$-Temperature of the gas at line conditions, in degree Rankine; $Z_{\mathrm{b}}$-Fluid compressibility at base conditions; $Z_{\mathrm{f}}$ Fluid compressibility at flowing conditions.

\section{Uncertainties}

Gases entering the Turbine meter shall be clean and free of any liquids and dust. A filter with $5 \mu \mathrm{m}$ filtration quality or better should be used if the gases are impure. The upstream pipe should also be cleaned before the installation of the meter. Maximum flow velocities can be up to 98.43 
$\mathrm{ft} / \mathrm{s}$ and excessive gas velocities can damage the meter, but $20 \%$ excess may be allowable for short periods. The Turbine meter is designed for horizontal orientation and shall be installed accordingly, as vertical orientation may introduce drags due to gravitational forces.

The linear performance for metering accuracy can be as good as \pm 0.5 for volume measurements on about $20: 1$ turndown ratio with repeatability of $\pm 0.02 \%$. The turndown ratio of a simple turbine meter increases proportionally with the square root of the gas density ratio. Griffiths et al. (1970) indicated in their studies that at a pressure of $290 \mathrm{psi}$, the turndown can be as high as 100:1 compared with 15:1 at working pressure close to atmosphere pressure. For each meter design and size, the manufacturer shall specify flow rate limits for $Q_{\min }, Q_{\mathrm{t}}$, and $Q_{\max }$. The performance for a turbine meter can be summarized as shown in Fig. 7. Where $Q_{\max }$ - The maximum gas flow rate through the meter that can be measured within the specified performance requirement $Q_{\min }-$ The minimum gas flow rate through the meter that can be measured within the specified performance requirement; $Q_{\mathrm{t}}$-The transition flow rate, the flow rate through the meter at which performance requirements may change.

\section{V-cone meter}

\section{Background information}

The V-cone meter (cone meter) was introduced in the late 1980s by McCrometer, it is a type of differential meters, but unique as this type of design constricts the flow by positioning a cone in the center of the pipe. The cone design forces the high velocity core to mix with the lower velocity flows closer to the pipe walls. This design also allows the flow profile to be flattened under extreme conditions

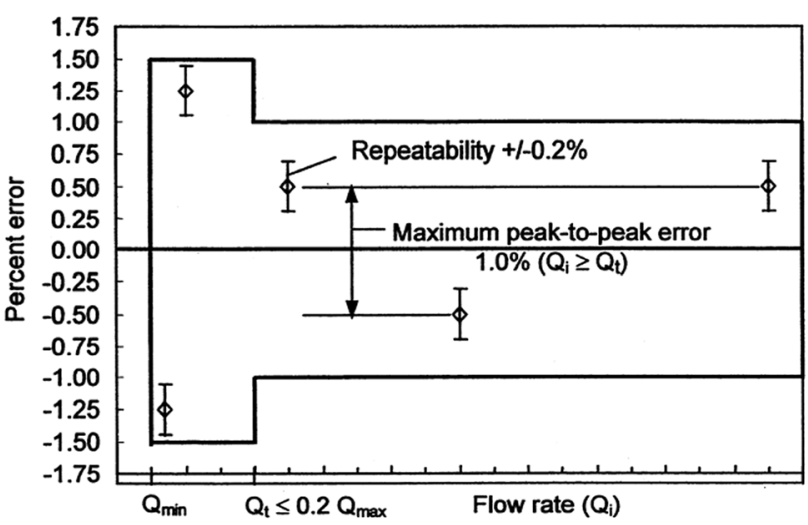

Fig. 7 Turbine meter tolerances at atmospheric pressure (AGA 7 2006) as V-cone forms very short vortices as the flow passes the cone. The low amplitude, high frequency signal produced by these short vortices ensures the stability of the signal. This implies that as different flow profiles approach the cone, there will always be a predictable flow profile at the cone, which ensures the measurement accuracy even in non-ideal conditions and reduces the permanent pressure loss. The cone meter is covered by international standards found in ISO 5167-5:2016.

\section{Design}

The V-cone meter, Fig. 8, is designed to minimize the pressure loss and withstand years of normal wear from erosion and corrosion without developing any significant shifts in calibration due to its $\mathrm{V}$-shaped restriction that has no critical surface dimensions or sharp edges that must remain within strict tolerances of original manufacture to maintain accuracy of measurement. Due to the geometry of the V-cone meter, it prevents the collection of any contaminates as flow passes through. The unique geometry of the V-cone also allows for a wide range of beta ratios, with standard beta ratios ranging from 0.45 to 0.75 . V-cone meters with values of beta ratios less than 0.45 are not normally manufactured while beta ratios larger than 0.75 require calibration. The $\mathrm{V}$-cone meter is installed such that the V-cone centreline is concentric to the centreline of the pipe section (ISO 51675, 2016).

There are two types of V-cone meter primary elements: the precision tube $\mathrm{V}$-cone meter range in line sizes from 0.5 to 150 inch (Fig. 9) and the Wafer-cone range from 1 to 6 inch (Fig. 10). McCrometer is the leading manufacturer for the V-cone meter as their most recent V-cone meter for the oil and gas industry consists of line sizes from 0.5 to 120 inch or larger with standard accuracy of $\pm 0.5 \%$,

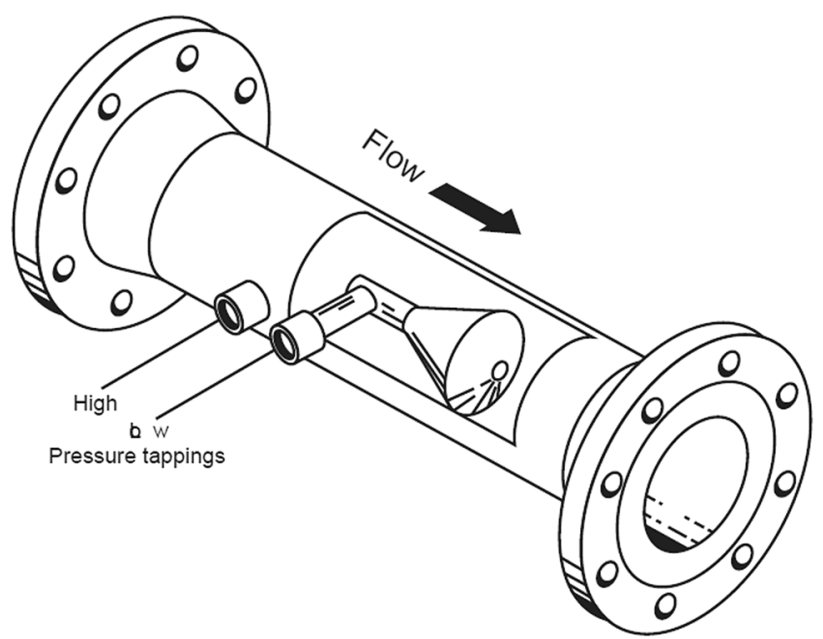

Fig. 8 McCrometer V-cone meter (Baker 2016)

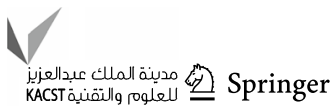


repeatability of $\pm 0.1 \%$ or better, and flow ranges of $10: 1$ and greater. Their V-cone meter consists of standard beta ratios ranging from 0.45 to 0.85 , with custom beta ratios available. The typical materials of the constructed V-cone meter include S304, S316, Duplex 2205 and 2507, Carbon steels, Hastelloy C276, 6Mo with end fittings consist of flanged, threaded, and hub or weld-end standard. It is typically installed zero to three diameters upstream and zero to one diameter downstream of the cone (McCrometer, 2018). As for their Wafer-cone, it can be installed within line sizes from 1 to 6 inch with $\pm 1.0 \%$ of accuracy, $0.1 \%$ or better for repeatability, and turndown ratio of 10:1. It consists of standard beta ratios ranging from 0.45 to 0.85 and the material of construction is typically 304 or 316 stainless steel. The installation for the Wafer-cone requires one to three diameters upstream and one diameter downstream of the cone (McCrometer 2013).

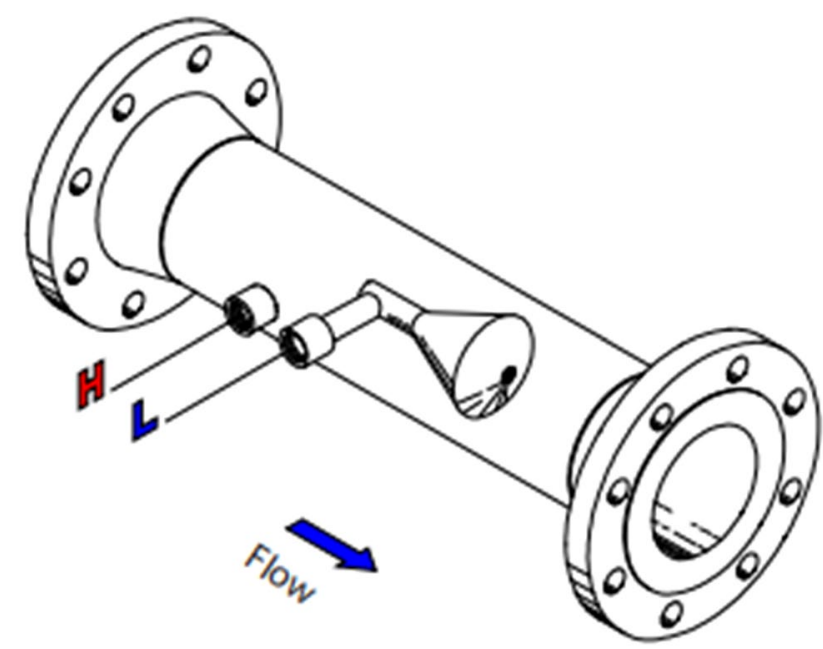

Fig. 9 McCrometer precision tube V-cone (McCrometer 2013)

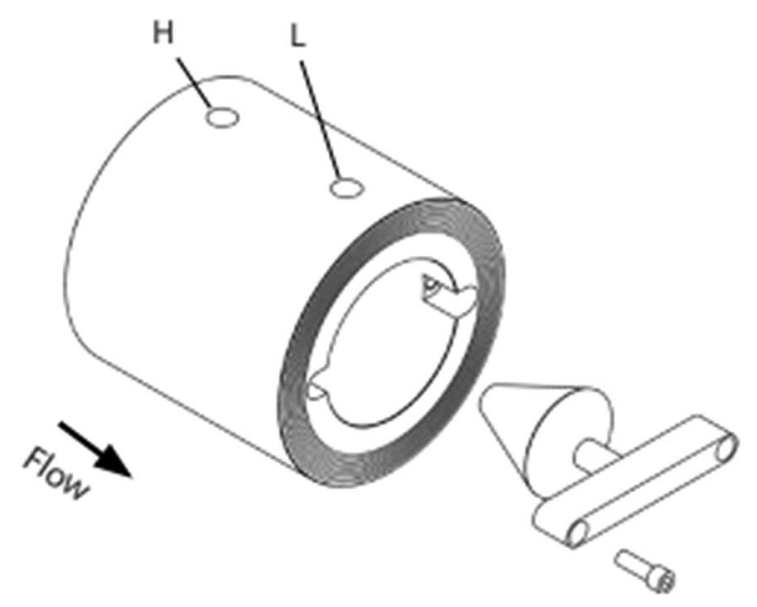

Fig. 10 McCrometer wafer-cone (McCrometer 2013)

\section{Measurement}

Flow equations for $\mathrm{V}$-cone flow meter are the actual volume flowrate (Eq. 8) and gas volume flowrate under standard condition (Eq. 9).

$Q=F_{\mathrm{a}} C_{\mathrm{D}} Y k_{1} \sqrt{\frac{\Delta p}{\rho}}$

$Q_{\mathrm{STD}}=Q \frac{p T_{\mathrm{b}} Z_{\mathrm{b}}}{p_{\mathrm{b}} T Z}$

where: $Q$-Actual volume flow, in cubic feet per hour; $Q_{\mathrm{STD}}$-Standard gas volume flow, in cubic feet per hour; $F_{\mathrm{a}}$-Material thermal expansion factor; $C_{\mathrm{d}}-$ Meter coefficient; $Y$ - Gas expansion factor; $k_{1}$-Flow constant; $\Delta p$ Differential pressure, in psi; $\rho$-Flowing density, in pounds per cubic feet; $p$-Operating pressure, in psi; $T_{\mathrm{b}}$ - Base temperature, in degree Rankine; $Z_{\mathrm{b}}$-Base gas compressibility; $p_{\mathrm{b}}$-Base pressure, in psia; $T$-Operating temperature, in degree Rankine; $Z-$ Gas compressibility.

\section{Uncertainties}

The V-cone meter can be accurate to $\pm 0.5 \%$ of reading in an ideal setting, with the level of accuracy dependent to a degree on application parameters and secondary instrumentation. It also exhibits excellent repeatability of $0.1 \%$ in terms of repeatability. Another huge advantage for the $\mathrm{V}$-cone meter is the turndown ratio, as the manufacturers claimed to be typically $10: 1$, which reaches a range far beyond the traditional DP meters. The standard beta ratio ranges from 0.45 through 0.75 and has a relatively low head loss that varies with beta ratio and differences in pressure. The V-cone forms relatively short vortices as the flow passes the cone as these short vortices create a low amplitude, high frequency signal. As compared to other differential pressure meters such as orifice meter, the V-cone has much higher signal stability as shown in Fig. 11.

Due to the design of the V-cone meter, it is effective for wet gas flow measurement applications especially when comparing to orifice meter. The cone-shaped design allows the amplitude of oscillation of the measured pressure field

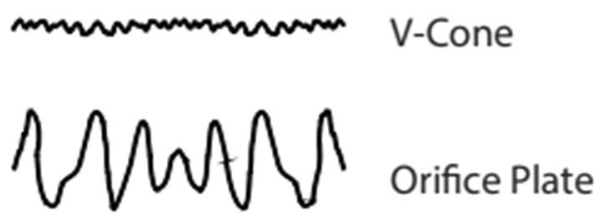

Fig. 11 DP Meter signal stability (McCrometer 2013) 
to be dampened and directs flow away from the critical edge to decrease corrosion to the meter. Manufacturers claim the $\mathrm{V}$-cone meter to be highly insensitive to velocity profile effects, thus requiring a much shorter upstream straight-pipe lengths compared to Orifice meter by a factor of up to 9 . The recommended installation for the $\mathrm{V}$-cone meter is zero to three pipe diameters of straight run upstream and zero to one pipe diameter downstream. The V-cone meter has been tested in several common configurations and proven to be within accuracy specifications, including close coupled with single $90^{\circ}$ elbows or double $90^{\circ}$ elbows out-of-plane (McCrometer 2013).

Szabo et al. (1992) studied the V-cone meter for natural gas flow and compared the flow equations to the standard orifice flow calculation equations. The experiment was conducted using a V-cone meter with 29.376 inch internal diameter and a cone diameter of 27.160 inch and compared to an Orifice meter with orifice plate bore diameter of 13.318-inches and meter tube diameter of 29.376in., as the two different meter specifications produce the same differential pressure under the same flow conditions. The investigation into the sensitivity of the governing flow rate equations shown that the two meters have the same characteristics and sensitivities to errors in terms of measured input values, including gas composition, temperature, pressure, and differential pressure. For the sensitivity to measured temperature, both meters shown $\mathrm{a} \pm 0.10 \%$ error in calculated flow rate for $\pm 1.0 \%$ error in temperature measurement. For the sensitivity to measured static pressure, both meters resulted in $\mathrm{a} \pm 0.06 \%$ error in calculated flow rate for $\mathrm{a} \pm 0.1 \%$ error in static pressure measurement. For sensitivity to measured differential pressure, both meters displayed $a \pm 0.4 \%$ error in calculated flow rate for $\mathrm{a} \pm 0.1 \%$ measurement error in differential pressure measurement.

Singh et al. (2006) conducted experiments using water and oil to cover a wide range of Reynolds number to study the effects of upstream flow disturbances by placing gate valve upstream of the $\mathrm{V}$-cone meter at a distance of five pipe diameter, ten pipe diameter and 15 pipe diameter and at $25 \%, 50 \%, 75 \%$, and fully open conditions of the valve. They found that the discharge coefficient is nearly independent of Reynolds number and has a weak dependence on the beta ratio. The discharge coefficient is also unaffected by the upstream disturbance at a distance of ten pipe diameters or more. However, for upstream disturbance less than ten pipe diameters, the maximum change in the discharge coefficient is approximately $6 \%$.

Liu et al. (2015) conducted numerical studies via CFD and experimental studies for verification to examine different beta edges of sharp angle, corner cut, and arc for beta ratios of $0.45,0.55$, and 0.65 . The results show that different beta edges cause different changes to the recirculation quantity and the dissipation in the cone wake flow region. From their
CFD-simulated data, the corner cut beta edge has the least discharge coefficient linearity error and also the least permanent pressure loss. Their experimental results demonstrate that the sharp angle beta edges have the best mechanical processing consistency while the arc beta edge performed the worst out of the three types.

V-cone meters require a high Reynolds number to measure correctly. In shale gas production, as gas flow rates drop and Reynolds number decreases with time, resize of meter and accurate measurement could be difficult in later life of a well based on our experiences.

\section{Orifice meter}

\section{Background information}

Orifice meter is one of the most widely used measuring devices for natural gas flow measurements. The theory orifice meter embodies on is given by Bernoulli's Equation. The name essentially describes the orifice plate itself as a plate with a hole machined into it, which is inserted into a pipe to measure the flowing fluid. As flow passes through, the constriction created by the orifice produces a pressure difference from the upstream to the downstream of the orifice plate. The most common type of orifice meters uses the square-edged concentric plates with flange taps for measuring points. The AGA Report No.3 provides the standard for this type of orifice meter set-up with the most readily available flow coefficients from extensive testing and studies.

Most of the early experimental works almost focused exclusively on the determination of discharge coefficients, with modern orifice meter for natural gas measurement dates back to early 1900s. Weymouth (1912) completed and published his experimental studies for orifice meter with a thin plate measured using flange taps. The orifice meter line was also in series with a pitot tube to make a comparison between the two, as availability of any orifice meter data was almost nonexistent as the time. Weymouth compared his study with published studies by Hodgson (1917) from England and had similar results despite the widely separated places and the experiments done independently. After Weymouth's publication, numerous other groups turned their attentions to the studies of orifice meter as the accumulated data and literatures eventually compiled into the first AGA report (1930), which is collected by a joint committee formed by AGA and American Society of Mechanical Engineers (ASME), with the National Bureau of Standards (NBS) for the review of the data. The establishment for the AGA Report No.1 upstarts the research projects on orifice meters, particularly the determination of the absolute values of orifice coefficients,

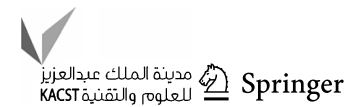


and eventually became the standard guideline for natural gas measurements using orifice meters in America.

Beitler (1935) led the largest single collection of experiments, also known as the Ohio State University (OSU) data base, for the determination of discharge coefficients for orifice meters from 1932 to 1933 sponsored by the industry. The experiments conducted using water flowing through seven pipe diameters ranging from one to $14 \mathrm{inch}$. The data from the smallest sizes are especially valuable since no data in pipes smaller than 2 inch were taken during the European and API tests. Buckingham (1932) and Bean (1935) of NBS develop a mathematical equation to calculate the flow coefficient for orifice meters using the OSU data base. The data base and equation were however, collected with water flows, indicating that any equations based on them require significant extrapolation in Reynolds number when used in high-pressure gas. The high quality of work became the base for all flange-tapped orifice metering standards until 1990.

Stolz (1978) combined the Beitler's data into a single, dimensionless equation applicable for all three pressure taps and adapted by for the international standard in the ISO standard 5167 (1980). This universal equation was eventually fortified using the much more comprehensive data base conducted over a ten-year period at eleven laboratories using four different fluids: oil, water, air, and natural gases, to cover the pipe Reynolds numbers ranging from 100 to 35,000,000. In the United States, Whetstone et al. (1988) conducted experiments with natural gas over the Reynolds number ranging from 25,000 to $16,000,000$ to measure the discharge coefficients of orifice for the 6 inch and 10 inch pipe diameters. The two-year collection of data contained 1,345 valid test points over eight beta ratios for the two selected pipe diameters. In 1988, a joint meeting of the United States and European flow measurement experts in New Orleans unanimously accepted the orifice plate discharge coefficient equation derived by the National Engineering Laboratory (NEL), based on the data collection from the past ten years in Europe and United States. ReaderHarris and Sattary (1990) describe the development of the discharge coefficient equation based on the physics of the orifice meter in their publication, as the equation is divided into tapping term, slope term, upstream and downstream tapping terms. Reader-Harris et al. (1995) further describe the two principal changes to the discharge coefficient equation previously accepted in 1988 based on the expanded collection of the orifice test data including the data collected in 2 inch and 24 inch pipes. The updated discharge coefficient equation includes the improved tapping terms for low Reynolds number and an additional term for small orifice diameter. The empirically derived discharge coefficient equation by the NEL set the standard for the discharge coefficient for both the ISO and the AGA for orifice metering.
The first edition of AGA Report No. 3 (1955) expanded the application conditions for orifice meter as well as setting the standard condition for pressure to 14.73 psia from the previous 14.4 psia. This report also introduces the formula using factors approach built upon the first law of thermodynamics in order to calculate the volumetric flow rate for the measured gas. The second edition of AGA Report No.3 (1985a). AGA-3 (1985b) expands the compressibility to cover a wider selection of gas composition as well as increasing the pressure up to 20,000 psi. The third edition of AGA Report No. 3 (1992) focuses on the flange-tapped orifice meter and provides the updated empirical coefficient of discharge equation for this type of pressure tap. This report also sets the revised standards with the recent extensive database conducted by the international standards that covers the range of beta ratios from 0.05 to 0.75 . The report also includes the uncertainty guidelines for calculating uncertainties using the equations. For orifice metering of gas measurements, the AGA-3 (2012) is the standard for natural gas industries in the United States.

The study of the velocity profiles and pressure profiles is essential in order to understand the fluid mechanics of differential pressure meters, particularly orifice meter. Durst et al. (1988) measured the flow velocities through a 1-inch orifice plate in a 2 inch pipe with Reynolds numbers ranging from 200 to 60,000 using LDV techniques. The experimental results demonstrate a similarity relationship of the maximum value of the Reynolds stress lines that is independent of Reynolds numbers. The experimental results are also compared with Durst and Wang (1989) numerical model using FVM, and the agreement between the results justifies the use of this computational approach for this type of orifice plate CFD models.

Morrison and his team from Texas A\&M University collected a very substantial amount of data by measuring velocity profiles and pressure profiles in orifice meter. Morrison et al. (1990) measured the flow field data through a 1 inch pipe and 0.5 inch orifice plate with airflow at a Reynolds number of 18,400 using 3-D LDV. DeOtte et al. (1991) measured the flow profile for a 1-inch orifice meter inside a 2 inch pipe operating with airflow at a Reynolds number of 54,700 using a 3-D LDV. Morrison et al. (1992a) measured the flow profile for a $1.5 \mathrm{inch}$ orifice meter inside a $2 \mathrm{inch}$ pipe operating with a constant mass flowrate using airflow at a Reynolds number of 91,100. The experiment used a flowconditioning unit to vary the inlet velocity while holding the mass flowrate constant. The results show the various inlet velocity profiles can affect the actual coefficient discharge significantly, as this variation correlates with the first-, second-, and third-order moments of momentum. Morrison et al. (1993) measured the flow field inside an orifice flowmeter with a beta ratio of 0.50 for a 2 -inch pipe operating at a Reynolds number of 91,000 using a 3-D LDV. This study 
examined a farther downstream location for the vena contracta and flow reattachment to the pipe wall for this setting. The experiment observed a small upstream recirculation zone and both a primary and secondary recirculation zone downstream of the orifice plate. The study also included the distributions of the entire Reynolds stress tensor and calculated into values of turbulence kinetic energy, turbulence kinetic energy production, vorticity, and turbulence induced accelerations, which further interpret the complex turbulent flow field inside an orifice meter.

These recent experiment studies, particularly the ones led by Morrison and his team, provided more in-depth measurements and studies into a deeper understanding of the fluid mechanics inside a pipe with the presence of different sizes of orifice meters. These studies established the foundations for further experimental works, including various conditions and factors that could affect the accuracy of the orifice measurements. The data also set the framework for numerical studies, such as simulating orifice meter with CFD models, as many of the recent numerical studies verifies their results with the data for from Morrison and his team, including our numerical studies on the orifice meter.

The flow through orifice meters is very difficult to describe mathematically, especially for turbulence gas flows. However, we can gain much insight by inspecting the various flow regimes that occur in an orifice flow to help us further understand flow mechanisms. (Upstream flow regime. Downstream flow regime: vena contracta, recirculation zones, sudden expansion, separate flow, reattach to the wall).

Perhaps the most important characteristic of an orifice meter, or any types of differential pressure flow meter, is the discharge coefficient, $C_{d}$, as it provides the ratio of the actual discharge to the theoretical discharge. The $C_{d}$ is a function of the Reynolds number and can be obtained by calibrating it in a flowing fluid. The extensive studies and research over the past in effort to determine the $C_{d}$, as $1 \%$ increase/decrease can affect directly to the flow volume by the same percentage. The latest standard, AGA No. 3 (2012), uses the discharge coefficient equation derived empirically by Reader-Harris and Gallagher (RG) determined from a vast collection of laboratory data. Reader-Harris and Gallagher developed this equation based on the understanding of orifice meter physics consists of the tapping term, the slope term consisting of throat Reynolds number term and velocity profile term, and upstream and downstream tapping terms (Reader-Harris 1990).

\section{Design}

By American Petroleum Institute (API) and AGA Standards, the primary element of the orifice meter consists of the orifice plate, the orifice plate holder (with its associated differential pressure sensing taps), and the meter tube as illustrated

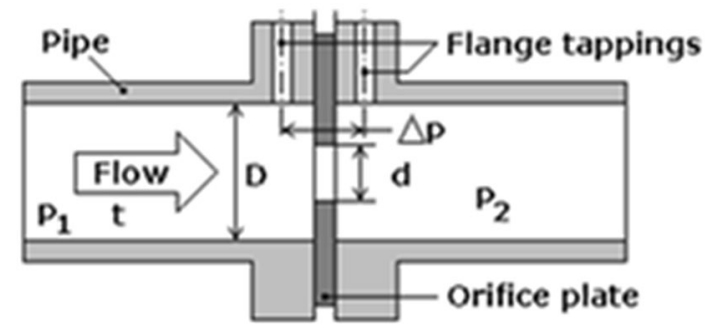

Fig. 12 Flange-tapped orifice meter (AGA 3.1 2012)

in Fig. 12. The orifice plate typically is a flat, thin plate consisting of a circular concentric aperture with a sharp, square edge. The orifice plate holder is used to contain and position the orifice plate in the piping system that functions as a pressure-containing piping element. The meter tube is the straight sections of pipe that include all segments that are integral to the orifice plate holder, upstream and downstream of the orifice plate. For Orifice meter to measure within the specified uncertainty, the measuring fluids have to be under steady-state mass flow conditions and considered to be clean, single phase, homogeneous, and Newtonian with pipe Reynolds numbers of 4,000 or greater (AGA-3.1 2012).

There are different locations for differential-pressure tappings: $\mathrm{D}$ and $\mathrm{D} / 2$ tapping (radius), pipe tapping ( $2 \frac{1}{2} \mathrm{D}$ and $8 \mathrm{D}$, full-flow), flange tapping, corner tapping, and vena contracta tapping. Vena contracta taps have been replaced by D and D/2 taps since today's taps require no tap relocation as vena contracta taps vary with changes in orifice beta ratio. Pipe taps are sometimes used as bypass pump restrictors for natural gas or where the other tapping arrangements require drilling too close to the plate. Corner and $\mathrm{D}$ and $\mathrm{D} / 2$ taps are widely used in Europe, while flange taps predominate in the United States for pipe sizes 2 inch and larger. The tappings should be positioned to prevent any unwanted component of the flowing line or any second phase in the flowing line from entering or being trapped in the impulse line. The orifice plate holder should maintain perpendicularly to the meter tube axis for dry gas applications. For moist gases, it should be positioned between angles of $30^{\circ}$ above the horizontal and vertically upward to the meter tube axis (Miller 1979). A pair of flange taps are located $1 \mathrm{inch}$ of the nearest plate face on the upstream side and 1 inch from the nearest plate face on the downstream side, measured from the center of the taps.

In terms of gas flow measurements, it should be designed carefully to accommodate for the changes in operating pressure and temperature since they can alter the gas density significantly during operation. Typically, flow computers are designed to obtain flow from sensors measuring the differential and static pressure, fluid temperature, and fluid density and/or specific gravity by either mechanical recording devices or electronic calculators. Although these secondary devices are 
not included within the scope of the API/AGA standards, they are essential for the precision in determining the flow rate of the measured gas flow.

At the pressure tap, the differential pressure element and the static pressure element can measure and record the pressures of the flowing gas. The differential pressure element measures and records $\Delta p, \Delta p_{\text {avg }}, \Delta p_{\text {rms }}, \Delta p_{t}$, while the static pressure element measures and records $p_{\mathrm{f}}$ (can also be measured with absolute static pressure $=$ gauge static pressure + local barometric pressure). The temperature element is installed in the flowing stream designated on the upstream or downstream location to measure and record $T_{\mathrm{f}}$. If the fluid velocity is higher than $25 \%$ of the fluid sound speed at the measuring point, corrections for the increase in temperature due to dynamic effects will have to be applied. The thermometer well is installed on the downstream side in between the dimension range of DL and 4DL to sense the average temperature of the fluid at the orifice plate (AGA-3.2 2012).

Daniel orifice plates can be installed within line sizes ranging from 0.25 to 24 inch while having a discharge coefficient
$Q_{\mathrm{v}}=C^{\prime} \sqrt{h_{\mathrm{w}} p_{\mathrm{f} 1}}$

where

$C^{\prime}=F_{\mathrm{n}}\left(F_{\mathrm{c}}+F_{\mathrm{sl}}\right) Y_{1} F_{\mathrm{pb}} F_{\mathrm{tb}} F_{\mathrm{tf}} F_{\mathrm{gr}} F_{\mathrm{pv}}$

- $F_{n}$ is the numeric conversion factor that combines the numeric element of the volumetric flow equation, which can be calculated through Eq. 12, where $E_{\mathrm{v}}$ is the velocity of approach factor calculated through Eq. 13.

$$
\begin{aligned}
& F_{\mathrm{n}}=338.196 E_{\mathrm{v}} D^{2} \beta^{2} \\
& E_{\mathrm{v}}=1 /\left(1-\beta^{4}\right)^{0.5}
\end{aligned}
$$

- $F_{\mathrm{c}}$ is the orifice calculation factor. The modification of the previous orifice meter coefficient discharge, $C_{\mathrm{d}}$, which is determined empirically from test data, is now the sum of $F_{\mathrm{c}}$ and $F_{\mathrm{sl}} . F_{\mathrm{c}}$ can be calculated through Eq. 14 . But if meter tubes internal diameter is less than 2.8 inch, Eq. 15 should be used to correct $F_{\mathrm{c}}$.

$$
\begin{aligned}
F_{\mathrm{c}}= & 0.5961+0.0291 \beta^{2}-0.2290 \beta^{8}+\left(0.0433+0.0712 e^{-8.5 / D}-0.1145 e^{-6.0 / D}\right)\left[1-0.23\left(\frac{19,000 \beta}{R e_{\mathrm{D}}}\right)^{0.8}\right] \frac{\beta^{4}}{1-\beta^{4}} \\
& -0.0116\left[\frac{2}{D(1-\beta)}-0.52\left(\frac{2}{D(1-\beta)}\right)^{1.3}\right] \beta^{1.1}\left[1-0.14\left(\frac{19,000 \beta}{R e_{\mathrm{D}}}\right)^{0.8}\right]
\end{aligned}
$$

uncertainty of \pm 0.5 to $0.75 \%$ with a $10: 1$ or better turndown ratio. Their plates are typically constructed with $316 / 316 \mathrm{~L}$ stainless steel with plate thickness ranging from 0.125 to 0.5 inch. The bore type of the plates includes concentric bore (bevel or no bevel), bore and counter bore, segmental, eccentric, quadrant round, and blank. Their standard for plate finish is typically less than 30 micro-inch of roughness (Emerson 2017).

Rosemount 3051SFC compact orifice flow meter can be installed within line sizes ranging from 0.5 to 12 inch with an accuracy of $\pm 1.30 \%$ of flow rate at 14:1 turndown ratio or $\pm 1.45 \%$ of flow rate at 8:1 turndown ratio. Rosemount 1495 orifice plates are configured as square-edged concentric bore and can be installed within line sizes ranging from 2 to $24 \mathrm{inch}$. Their plates are typically constructed with $316 / 316 \mathrm{~L}$ stainless steel or 304/304L stainless steel and with plate thickness ranging from 0.125 to 0.5 inch (Emerson 2021a).

\section{Measurement}

Gas flow volume can be calculated using the most recent and updated gas flow rate equation for flange-tapped Orifice meter published by AGA in 2012 below in field units (AGA 3.3, 2012), Nomenclature is available in Table 1.
$F_{\mathrm{c}}=F_{\mathrm{c}, \mathrm{ld}}+0.003(1-\beta)(2.8-D)$

- $F_{\mathrm{sl}}$ is the orifice slope factor. It is the slope term from the coefficient of discharge equation and is a function of $R e_{\mathrm{D}}$ and $\beta$. For most natural gases, $R e_{\mathrm{D}}$ can be estimated using Eq. 16, which is a function of $Q_{\mathrm{v}}, D$, and $G_{\mathrm{r}}$. Since $R e_{\mathrm{D}}$ is a function of $Q_{\mathrm{v}}$, it can only be obtained through iteration. Typically, three iterations of $\mathrm{Q}_{\mathrm{v}}$ and $R e_{\mathrm{D}}$ are required to provide an accurate solution for $R e_{\mathrm{D}}$. After obtaining the value for $R e_{\mathrm{D}}$, the orifice slope factor can be calculated using Eq. 17.

$$
\begin{aligned}
R e_{\mathrm{D}}= & 47.0723 \frac{Q_{\mathrm{v}} G_{\mathrm{r}}}{D} \\
F_{\mathrm{sl}}= & 0.000511\left(\frac{1,000,000 \beta}{R e_{\mathrm{D}}}\right)^{0.7} \\
& +\left[0.0210+0.0049\left(\frac{19,000 \beta}{R e_{\mathrm{D}}}\right)^{0.8}\right] \beta^{4} \\
& \times\left(\frac{1,000,000 \beta}{R e_{\mathrm{D}}}\right)^{0.35}
\end{aligned}
$$


Table 1 Nomenclature in the gas volume calculation (AGA 3.3, 1992)

\begin{tabular}{|c|c|}
\hline Symbol & Description \\
\hline$C^{\prime}$ & Composite orifice flow factor \\
\hline$C_{\mathrm{d}}(\mathrm{FT})$ & Coefficient of discharge at a specific pipe Reynolds number for a flange-tapped orifice meter \\
\hline$C_{\mathrm{i}}(\mathrm{CT})$ & Coefficient of discharge at an infinite pipe Reynolds number for a corner-tapped orifice meter \\
\hline$C_{\mathrm{i}}(\mathrm{FT})$ & Coefficient of discharge at an infinite pipe Reynolds number for a flange-tapped orifice meter \\
\hline$D$ & Meter tube internal diameter calculated at flowing temperature $\left(T_{f}\right)$, in inch \\
\hline$D_{\mathrm{r}}$ & Reference meter tube internal diameter calculated at reference temperature $\left(T_{r}\right)$, in inch \\
\hline$D$ & Orifice plate bore diameter calculated at flowing temperature $\left(\mathrm{T}_{\mathrm{f}}\right)$, in inch \\
\hline$d_{\mathrm{r}}$ & Reference orifice plate bore diameter calculated at reference temperature $\left(T_{r}\right)$, in inch \\
\hline$e$ & Napierian constant, 2.71828 \\
\hline$E_{\mathrm{v}}$ & Velocity of approach factor \\
\hline$F_{\mathrm{c}}$ & Orifice calculation factor \\
\hline$F_{\mathrm{gr}}$ & Real gas relative density factor \\
\hline$F_{\mathrm{n}}$ & Numeric conversion factor \\
\hline$F_{\mathrm{pb}}$ & Base pressure factor \\
\hline$F_{\mathrm{pv}}$ & Supercompressibility factor \\
\hline$F_{\text {sl }}$ & Orifice slope factor $^{1}$ \\
\hline$F_{\mathrm{tb}}$ & Base temperature factor \\
\hline$F_{\text {tf }}$ & Flowing temperature factor \\
\hline$G_{\mathrm{i}}$ & Ideal gas relative density (specific gravity) \\
\hline$G_{\mathrm{r}}$ & Real gas relative density (specific gravity) \\
\hline$h_{\mathrm{w}}$ & Orifice differential pressure, in inch of water at $60^{\circ} \mathrm{F}$ \\
\hline$K$ & Isentropic exponent \\
\hline$k_{\mathrm{p}}$ & Perfect gas isentropic exponent \\
\hline$L_{1}, L_{2}$ & $L_{1}=L_{2}$, dimensionless correction for tap location, $N_{4} / D$ for flange taps \\
\hline $\mathrm{Mr}_{\text {air }}$ & Molecular weight of air, in pounds mass per pound-mole \\
\hline $\mathrm{Mr}_{\text {gas }}$ & Molecular weight of gas, in pounds mass per pound-mole \\
\hline$N_{4}$ & 1.0 when $D$ is in inch \\
\hline$P_{\mathrm{b}}$ & Base pressure, in pounds force per square inch absolute \\
\hline$p_{\mathrm{f} 1}$ & Absolute flowing pressure (upstream tap), in pounds force per square inch absolute \\
\hline$Q_{\mathrm{v}}$ & Volume flow rate at standard conditions of $Z_{b}, T_{b}$, and $P_{b}$, in cubic feet per hour \\
\hline$R e_{\mathrm{D}}$ & Pipe Reynolds number \\
\hline$T_{\mathrm{b}}$ & Base temperature, in degreesRankine \\
\hline$T_{\mathrm{f}}$ & Absolute flowing temperature, in degrees Rankine \\
\hline $\operatorname{Tr}$ & Reference temperature of the orifice plate bore diameter and/or meter tube inside diameter, in degrees Fahrenheit \\
\hline$Y_{1}$ & Expansion factor based on upstream absolute static pressure \\
\hline$Z_{\mathrm{b}}$ & Compressibility at base conditions $\left(P_{b}, T_{b}\right)$ \\
\hline$Z_{\mathrm{f} 1}$ & Compressibility at upstream flowing conditions $\left(P_{f l}, T_{f}\right)$ \\
\hline$\alpha_{1}$ & Linear coefficient of thermal expansion of the orifice plate material, in inch $/$ inch- ${ }^{\circ} \mathrm{F}$ \\
\hline$\alpha_{2}$ & Linear coefficient of thermal expansion of the meter tube material, in inch/inch- ${ }^{\circ} \mathrm{F}$ \\
\hline$\beta$ & Ratio of orifice plate bore diameter to meter tube internal diameter $(d / D)$ calculated at flowing temperature $\left(T_{f}\right)$ \\
\hline$\mu$ & Absolute viscosity of flowing fluid, in pound mass per feet-second \\
\hline
\end{tabular}

- $Y_{1}$ is the expansion factor referenced to upstream pressure. It depends on the expansion of gas through the orifice. The expansion factor corrects for the variation in density since the density of the stream changes due to the pressure drop and the adiabatic temperature change. It is a function of the differential pres- sure, the absolute pressure, the diameter of the pipe, the diameter of the orifice, and the type of taps, and the isentropic exponent. Typically for natural gas applications, the perfect gas isentropic exponent, $k_{\mathrm{p}}$, is used as $k_{\mathrm{p}}=k=1.3$. For the calculation of $Y_{1}$, Eq. 19 can be used to calculate $Y_{1}$ as long as the criterion for Eq. 18 
is valid. If upstream static pressure is measured to calculate volumetric flow, Eq. 20 is used to calculate the ratio of differential pressure to absolute static pressure, $x_{1}$. The ratio of $x_{1}$ and $k$ is also known as the acoustic ratio.

$0<\frac{h_{\mathrm{w}}}{27.707 p_{\mathrm{f}}} \leq 0.20$

$Y_{1}=1-\left(0.41+0.35 \beta^{4}\right)\left(\frac{x_{1}}{k}\right)$

$x_{1}=\frac{h_{\mathrm{w}}}{27.707 p_{\mathrm{f}_{1}}}$

- $F_{\mathrm{pb}}$ is the base pressure factor which is a direct application of Boyle's law in order to calculate the difference in base pressure, $p_{\mathrm{b}}$, from 14.73 psia.

$F_{\mathrm{pb}}=\frac{14.73}{p_{\mathrm{b}}}$

- $F_{\mathrm{tb}}$ is the base temperature factor which is a direct application of Charles's law in order to calculate the difference in base temperature change.

$F_{\mathrm{tb}}=\frac{T_{\mathrm{b}}}{519.67}$

- $F_{\mathrm{tf}}$ is the flowing temperature factor which is used to correct the effects of temperature variation. Higher flowing temperature implies a lighter gas which led to increases in flow, but it also causes the gas to expand, which reduces the flow. The flowing temperature factor is usually applied to the average temperature during the time gas is passing through.

$F_{\mathrm{tf}}=\sqrt{\frac{519.67}{T_{\mathrm{f}}}}$

- $F_{\mathrm{gr}}$ is the real gas relative density factor which is used to correct for changes in the specific gravity based on the actual flowing specific gravity of the gas, which is updated constantly by a recording gravitometer or by gravity balance. Since the basic orifice factor is determined by air with a specific gravity of 1 , it is expressed as:

$F_{\mathrm{gr}}=\sqrt{\frac{1}{G_{\mathrm{r}}}}$

- $F_{\mathrm{pv}}$ is the supercompressibility factor which is used to correct for the fact that gas does not behave exactly as the ideal gas law stated, but all gases do deviate from this ideal gas law to a greater or lesser extent. The term supercompressibility accounts for the deviation between the actual density of a gas under high pressure and the theoretical density obtained by the base conditions. $z_{b}$ is the gas compressibility at the base conditions, $z_{\mathrm{f}}$ is the gas compressibility at operating/flowing conditions.

$F_{\mathrm{pv}}=\sqrt{\frac{z_{\mathrm{b}}}{z_{\mathrm{f} 1}}}$

- Typically, the gas volume is calculated through measured data of differential pressure, daily average pressure, flowing temperature, and flow hours, along with the provided gas composition, orifice plate size, and the pipe size. The differential pressure data is the input for $h_{\mathrm{w}}$ and the daily average pressure data is the input for $p_{\mathrm{f} 1}$ in Eq. 10. For a more precise calculation, the orifice plate bore diameter (Eq. 26) and the meter tube internal diameter (Eq. 27) should be calibrated with the flowing temperature data used as $T_{\mathrm{f}}$. The reference temperature, $T_{\mathrm{r}}$, per AGA standard is assumed to be at $68^{\circ} \mathrm{F}$. The linear coefficient of thermal expansion, $\alpha_{1}$ and $\alpha_{2}$, can found through ASME database for $-100^{\circ} \mathrm{F}$ to $+300^{\circ} \mathrm{F}$ or API database for $-7^{\circ} \mathrm{F}$ to $154^{\circ} \mathrm{F}$. For our cases, we typically use orifice plate and pipe constructed materials of type 304 and 316 stainless steel with $\alpha$ value of 0.00000925 .

$$
\begin{aligned}
& d=d_{\mathrm{r}}\left[1+\alpha_{1}\left(T_{\mathrm{f}}-T_{\mathrm{r}}\right)\right] \\
& D=D_{\mathrm{r}}\left[1+\alpha_{2}\left(T_{\mathrm{f}}-T_{\mathrm{r}}\right)\right]
\end{aligned}
$$

The new calculation does not require readings from AGA's published tables to obtain factor/coefficients in Eq. 11. The factors are calculated through the measured parameters as well as gas properties, including specific gravity and Z-factor. The ideal gas specific gravity, $G_{\mathrm{i}}$, is calculated as the ratio of the molecular weight of the measured gas, $\mathrm{Mr}_{\mathrm{gas}}$, to the molecular weight of the air, $\mathrm{Mr}_{\text {air }}$, in Eq. 28, with $\mathrm{Mr}_{\text {air }}=28.9625$ pounds mass per pound-mole. The real gas specific gravity, $G_{r}$, is calculated through Eq. 29, with the $Z$-factor for air at base conditions, $Z_{\text {bair }}=0.999590$.

$$
\begin{gathered}
G_{\mathrm{i}}=\frac{\mathrm{Mr}_{\mathrm{gas}}}{\mathrm{Mr}_{\mathrm{air}}} \\
G_{\mathrm{r}}=G_{\mathrm{r}} \frac{Z_{b_{\text {air }}}}{Z_{b_{\text {gas }}}}
\end{gathered}
$$

The $Z$-factor for gas is calculated through the equation of state fitted by Dranchuk and Abou-Kassem (1975) to the data of Standing and Katz (1942), as their method is 
more convenient for estimating the $\mathrm{z}$-factor for gas with computer programs. For orifice metering of natural gases, we are typically dealing with low-temperature conditions, hence the bisection method is applied to estimate the Z-factor through iterations instead of using the Newton-Raphson method, as the latter becomes unstable and perform slower at low temperature conditions.

The discharge coefficient for orifice meter, $C_{\mathrm{d}}$, has been correlated from test data as a function of diameter ratio, meter tube diameter, and pipe Reynolds number. For a concentric, square-edged flange-tapped orifice meter, $C_{\mathrm{d}}$ (FT) can be calculated as the sum of the orifice calculation factor, $F_{\mathrm{c}}$, and the orifice slope factor, $F_{\mathrm{sl}}$, as shown in Eq. 30 using the factors approach. The equation is applicable to nominal pipe sizes of 2 inch and larger while within the beta ratio range of 0.1 to 0.75 , provided that the orifice plate bore diameter is greater than $0.45 \mathrm{inch}$, and also a pipe Reynolds number greater than or equal to 4000 . For meter tube with internal tube diameter less than 2.8 inch, $F_{\mathrm{c}}$ should be modified accordingly as shown in Eq. 15 . For typical operating gas flow range, the pipe Reynolds numbers exceed the requirement in orders of magnitude.

$C_{\mathrm{d}}(\mathrm{FT})=F_{\mathrm{c}}+F_{\mathrm{sl}}$

The discharge coefficient can also be calculated with the RG equation as follows:

$C_{\mathrm{d}}(\mathrm{FT})=C_{\mathrm{i}}(\mathrm{FT})+0.000511\left(\frac{10^{6} \beta}{R e_{\mathrm{D}}}\right)^{0.7}+(0.0210+0.0049 A) \beta^{4} C$

$C_{\mathrm{i}}(\mathrm{FT})=C_{\mathrm{i}}(\mathrm{CT})+$ Tap Term

$C_{\mathrm{i}}(\mathrm{CT})=0.5961+0.0291 \beta^{2}-0.2290 \beta^{8}+0.003(1-\beta) M_{1}$

Tap Term $=$ Upstrm + Dnstrm

Upstrm $=\left[0.0433+0.0712 e^{-8.5 L_{1}}-0.1145 e^{-6.0 L_{1}}\right](1-0.23 A) B$

Dnstrm $=-0.0116\left[M_{2}-0.52 M_{2}^{1.3}\right] \beta^{1.1}(1-0.14 A)$

where

$B=\frac{\beta^{4}}{1-\beta^{4}}$

$M_{1}=\max \left(2.8-\frac{D}{N_{4}}, 0.0\right)$

$M_{2}=\frac{2 L_{2}}{1-\beta}$
$A=\left(\frac{19,000 \beta}{\operatorname{Re}_{\mathrm{D}}}\right)^{0.8}$

$C=\left(\frac{10^{6}}{R e_{\mathrm{D}}}\right)^{0.35}$

The computer codes we have developed allow pipe Reynolds number to be updated simultaneously based on flow data and plate sizes that provides calculations that are more precise. The discharge coefficients for the Reynolds number iterations are calculated using Eq. 31 through Eq. 32, as the factor approach is not feasible for the iterating.

\section{Uncertainties}

Orifice meter is typically simple, inexpensive, consisting of no moving parts, mechanically stable, and has no limitation on temperature, pressure, or size. Orifice meters for gas measurement are considered to be accurate to \pm 1 to $\pm 2 \%$, accuracies better than $\pm 1 \%$ can be achieved by individual calibration. However, it tends to have relative low accuracy when measuring at low flow conditions. The turndown for this design typically is less than 5:1, which is a relatively low range compared to other meters. It also has high-pressure loss (15-55\%) which can impact operating cost. Orifice meter is also flow-profile sensitive and usually requires a long meter tube or flow conditioner, and it is not capable of self-cleaning thus can be easily damaged or clogged by high flow rates.

The AGA-3 equation and the Reader-Harris/Gallagher equation were developed implicitly assuming that the velocity profile in the upstream of the orifice is fully developed, symmetric, swirl-free, and turbulent for the orifice meter to measure accurately. However, this is not always the case for the field measurement as different factors can affect the flow profile and the "pureness" of the flowing gas, which could possibly affect the accuracy of the orifice measurement. Extensive studies on different factors are reviewed in each of the sub-sections as how each factor affects the measurement accuracy.

\section{Installation effects}

The orifice coefficient equations were developed assuming the upstream axial velocity profile is "fully developed" as it implies that the discharge coefficient would not change if the meter tube were lengthened further. However, standard pipefittings such as tees, elbows, and valves from the upstream of the pipe can introduce velocity profile distortion and increase turbulence levels with significant swirl velocity component. The effect of a peaked velocity profile increases 
the discharge coefficient, whereas a flattened profile will reduce the discharge coefficient. An asymmetric flow will reduce the discharge coefficient since it would require more energy to move an asymmetric flow through the orifice than a symmetrical flow. The effect of swirl increases the discharge coefficient as it would increase the diameter of the vena contracta.

Morrow et al. (1991) performed experimental studies to measure the upstream velocity profiles for a $45 \mathrm{D}$, four-inch diameter meter tube using nitrogen flow at a Reynolds number of $9 \times 10^{5}$ with orifice plate in beta ratios of 0.40 and 0.75 . The measured velocity profiles were compared to the power law velocity profile model and the modified logarithmic velocity profile model. The results show that the flow is still far from fully developed in a length of 45D as a greater meter tube length or flow conditioners may be needed.

Morrison et al. (1992) investigated the effect of the inlet velocity distribution upon the discharge coefficient in a two inch pipe with beta ratio of 0.75 using airflow at a Reynolds number of 91,000 . The velocity profiles obtained are compared with the profiles measured using a laser Doppler velocimeter. The experimental study shows that the upstream velocity profile can affect the discharge coefficient significantly and the changes in discharge coefficient are correlated with the first-, second-, and third-order moments of momentum.

\section{Swirl}

Like most of the flow meters, orifice meter is affected by how and where it is installed. Orifice meters need to be calibrated according to the AGA 3.2 guidelines to give a predictable performance when installed where the flow profile approximates to a fully developed flow profile at the Reynolds number of the flow. A fully developed turbulent velocity profile is symmetric around the pipe axis with maximum fluid velocity at the axial centerline of the pipe. The Reader-Harris/Gallagher (RG) equation used to develop the discharge coefficient implicitly assumes that the velocity profile is fully developed, symmetric, swirl-free, and turbulent. Installation effects may disturb the flow profile that could lead to a change in the metering performance and the effect of upstream fittings and pipework is considered in terms of peaks of profile, asymmetry, and swirl (ReaderHarris 2015). The effect of a peaked profile, for example, to a roughened pipe, is to reduce the pressure drop for a given flowrate and thus increase the discharge coefficient. On the contrary, the effect of a flattened profile will reduce the discharge coefficient. An asymmetric flow reduces the discharge coefficient since more energy is required to move an asymmetric flow through the Orifice as compared to the same flow flowing symmetrically. The effect of swirl is more complex as it is almost always accompanied by a change in axial velocity profile. The velocity profile from the swirl effect is flattened and typically asymmetric which reduces the discharge coefficient and under measures the flowrates.

A flow conditioner may be used to improve the velocity profile from the effect of swirl. According to AGA 3.2, flow conditioners can be classified into straighteners or isolating flow conditioners. Flow straighteners are devices that effectively remove or reduce the swirl component of a flowing stream but may have limited ability to produce the flow conditions necessary to accurately replicate the discharge coefficient values. Isolating flow conditioners are devices that effectively remove the swirl component from the flowing stream while redistributing the stream to produce the flow conditions that accurately replicate the discharge coefficient (AGA 3.2, 2012).

Shen (1991) investigated effects of swirl on the measurement accuracy of a 6-inch orifice meter with airflow using an axial vane-type swirler. Shen conducted experiments separately for the velocity profile and orifice meter performance with swirl angle ranging from $-30^{\circ}$ to $+30^{\circ}$. The results showed the swirling flows can cause an up to $5 \%$ under-measurement on orifice metering accuracy, whereas beta ratio and flow rate have much less effects on the meter's performance. The swirl also flattens the axial velocity profiles compared to the power-law profile for turbulent flow in smooth pipes. The study included the test of the tube bundle conditioner as well, which can significantly reduce the effects of the swirl and to some extent cause the orifice meter to over-measure the true flow rate slightly. Reader-Harris (1994) studied the decay of swirl in a pipe through extensive mathematical equations based on the approximation to the Navier-Stokes equations. He simplifies the Navier-Stokes equations by introducing an order-of-magnitude analysis and a turbulent viscosity to solve the swirl equation. After verifying with experimental data, the study concludes the swirl will be extremely persistent in smooth pipes at high Reynolds number, but flow straighteners are recommended for the measurement accuracy of orifice meter. Morrison et al. (1995) studied the effect of a concentric tube flow conditioner and a vane-type swirl generator for different orifice plate sizes with beta ratios of $0.43,0.45,0.484,0.55$,
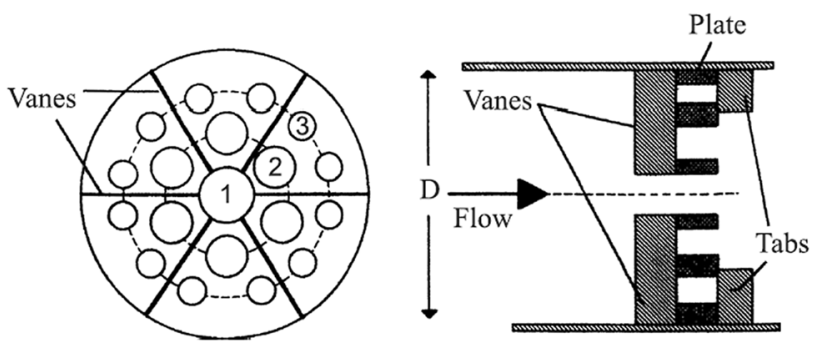

Fig. 13 Vaned-plate flow conditioner (Ouazzane and Behnhadj 2002) 
$0.6,0.65,0.7$, and 0.726 in a 2-inch pipe with Reynolds number of 91,100 and 120,000 . The data provides optimal orifice beta ratios for installation in cases that swirl effect is expected to dominate the flow.

\section{Flow conditioner}

Upstream disturbances can be reduced through flow straighteners and/or flow conditioners. Flow straighteners eliminate swirl from the inlet flow but has little or no effect on the upstream velocity profiles. They are only effective for orifice plate with small beta ratio. Typical flow straighteners are installed in the forms of tube bundles. Flow conditioners, on the other hand, not only eliminate swirl but also produces a repeatable downstream velocity profile, regardless of upstream flow disturbances.

Ouazzane and Behnhadj (2002) studied two flow conditioners for orifice meter, vaned-plate flow conditioner (Fig. 13) and NEL-plate flow conditioner. For vaned-plate, orifice meter performance improves at high operating Reynolds numbers regardless of the beta ratio and the severity of the distortions in the upstream flow. For NEL-plate, the errors at low and moderate Reynolds numbers were still significant and inefficient in short installations.

\section{Chemical and organic contamination}

The flowing fluids, such as oil, grease, pipeline sludge or other liquids or solids, can contaminate orifice plates. The accumulation of such contaminates can also build up flow restrictions inside the pipe and on the orifice plate, which would create additional pressure drop for the flowing fluid. One of the common contamination related problems is black powder, which is made up of various corrosive materials in forms of iron sulfide, iron oxide, hydrocarbons, and asphalt components.

Tsochatzidis (2008) performed experimental analysis of the black powder to study its effect on gas metering equipment. The black powder he collected consists of about $80 \%$ corrosion products while the rest is made up of typical soil minerals. From the examination of the orifice plate, he found a thick layer of black powder mixing with oil or grease on the upstream face of orifice plates from the Sidirokastro border metering station. Contamination of black powder was found in other instruments and installations as well, including pressure measurements, water dewpoint analyzer, gas chromatographs, specific gravity meters, and online densitometers. The effect of black powder causes these instruments to deviate beyond acceptable tolerance of the standards and cause permanent damage to the instruments as well as the installations. Black powder contamination was also present for the inner pipe wall and decreased the pipe roughness by smoothing the rougher surfaces. In another study by
Trifilieff and Wines (2009), they found the opposite as black powder increases the interior pipe wall surface roughness, and to some extents, the accumulation of the black powder to a sufficient level creates a flow restriction for the path. For either case, the changes in pipe wall roughness affect the discharge coefficient and alter the velocity profiles for the flowing fluids, thus increasing the uncertainty in orifice measurements.

Reader-Harris et al. (2012) conducted experimental work in conjunction with CFD simulations to examine the effects of contamination on the orifice plate from the upstream side. His laboratory works and CFD models included orifice plates with beta ratios of $0.2,0.4,0.6$, and 0.75 with pipe diameter of 11.81-inch, with 35 simulation runs at a pipe Reynolds number of $10^{7}$ and three runs at a pipe Reynolds number of $10^{6}$ using nitrogen gas as the flowing fluid. The CFD models overall are in remarkably good agreement with the experimental results. The contamination layer was simulated on the upstream face of the orifice plate using uniform layer with thickness $h$ and an angle $\theta$ created by the distance from the plate edge $r$, as shown in Fig. 14. The contamination layer increased the size of the vena contracta and reduced the pressure difference across the plate and increase the discharge coefficient as compared to the results simulated from a clean orifice plate. To analyze how each contamination layer parameters can affect the discharge coefficient, he also performed parametric studies using parameters $h$ and $r$ for different beta ratios. The results showed the thickness of the contamination layer $h$ has a much larger impact on the discharge coefficient than the radius of the contamination layer $r$.

Li et al. (2013) studied the effect of sludge deposition on orifice metering accuracy through CFD simulations for a 2 -inch pipe with beta ratio of 0.75 using water as the flowing fluid. The sludge deposition, shown in Fig. 15, was simulated with inlet velocities of 4.0, 8.0,12.0, 16.0, and $20.0 \mathrm{~m} / \mathrm{s}$ using degrees of 0.1 to 1.0 and verified with experimental

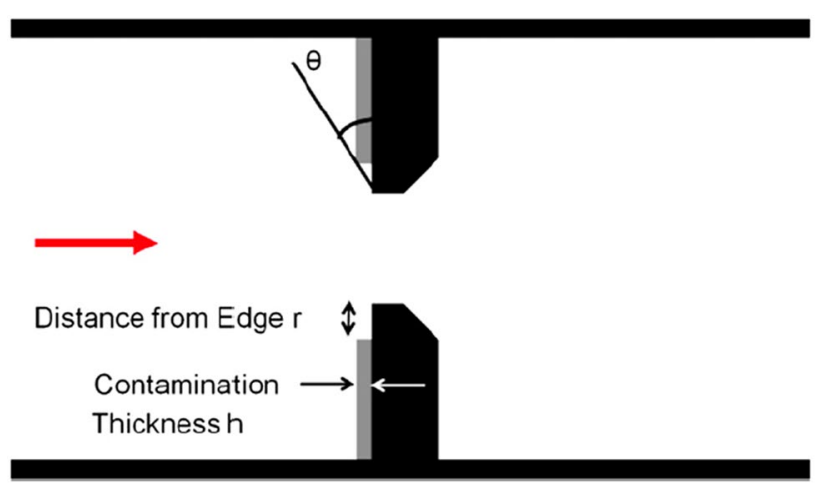

Fig. 14 Geometry used in orifice contamination simulations (ReaderHarris et al. 2012) 
Fig. 15 Schematic of the orifice plate deposition ( $\mathrm{Li}$ et al. 2013)
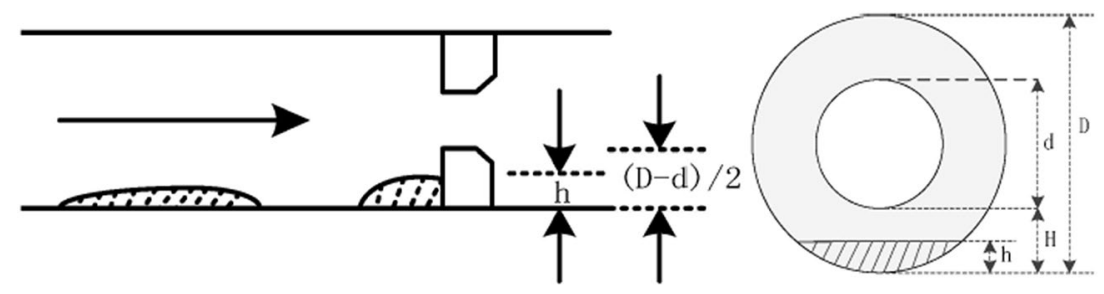

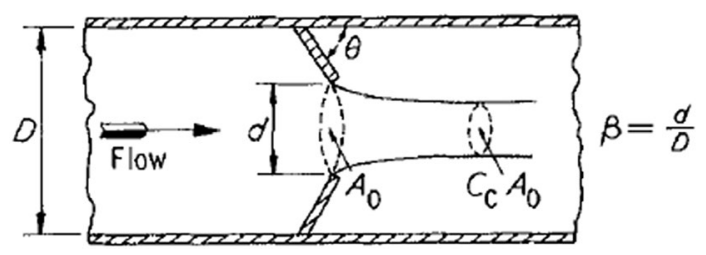

Fig. 16 Effect of orifice-plate buckling on the coefficient of contraction (Jepson and Chipchase 1975)

results using deposition degrees of $0.25,0.5,0.75$, and 1.0, as deposition degree, $Y_{u}$, is defined as $h /[0.5(D-d)]$, with $h$ as the deposition height. Simulation results show that the deposition affects the downstream pressure significantly and causes an increase in terms of discharge coefficients of the orifice. The changes in discharge coefficients also increase with higher degrees of depositions. Their models provide a method for further CFD studies for deposition effects on orifice meter, which can be related to similar effects such as contamination, wear conditions, and etc. Their studies also provide us insights on how to perform discharge coefficient calculations for CFD models based on AGA standards. However, since their models are based on water as the flowing fluid with beta ratio of only 0.75 , we should establish our CFD models using gas (air) as the flowing fluid with a more reasonable beta ratio, preferably a beta ratio of 0.50 before we develop further into this type of models.

\section{Physical deformation}

Benedict et al. (1974) inv estigated the effect of edge sharpness on the discharge coefficient of an orifice plate through experimental studies. The edge roundness of the orifice plates are measured based on the optical method, which uses the projection from a fine beam of light directed at the orifice edge in conjunction with a geometric equation to determine radius of curvature of the orifice edge. The roundness measurements are in good agreement compared with the lead foil method measurements provided by Daniel Industries, Inc. The experiments are conducted using five random orifice plates, significantly different in terms of measured edge sharpness, set-up in a 4 inch pipe to measure the discharge coefficients. By comparing the results from Crockett and Upp (1973) and Brain et al. (1973) with their similar experimental studies, the edge sharpness of the upstream face of an orifice plate has a significant effect on the discharge coefficient of an orifice meter; this effect can be quantified especially with further studies and data collections.

Jepson and Chipchase (1975) investigated into the effect of plate buckling on orifice meter accuracy through experimental studies (Fig. 16). The orifice plate will always experience elastic deformation during operation, as the measuring fluids are flowing with high velocities that generate deflections on the plate. The experiments were conducted using orifice plates with beta ratios of 0.2 and 0.7 through an 8-inch pipe, with bore deflections of $0,1 / 32,1 / 16,1 / 8$, $1 / 4,3 / 8$, and $1 / 2$ inch relative to the support using natural gas as the testing fluid. The tangential stress generated from the buckling effect causes a decrease in the orifice bore diameter, thus result in a flow over-estimation. However, the coefficient of contraction will increase due to the elastic deformation, which results a drop in the differential pressure and an under-registration in flow. These two opposite effects will partially cancel each other and causes an under-measurement of the flow; the flow measurement error due to elastic defection can be quantified in terms of geometry and the mechanical properties of the buckled orifice plate. Norman et al. (1989) further investigated into elastic deformation of the orifice plate through static loading test to verify their theoretical developed equation describing the under-registration of the flow. They also found that orifice plate exhibits a nonlinear relationship between deflection and load, whereas the flow error equation is based on a linear elastic theory. However, the change in slope of the orifice plate deflection and the flow error follow a linear relationship, thus eliminates the need to know the modulus of elasticity of the plate material as the error can be directly related to deformation.

Norman et al. (1989) also studied the effects of plate eccentricity through a 5.9-inch pipe using beta ratios of 0.2 , $0.37,0.57,0.66$, and 0.75 for $D+D / 2$ and flanged tapped orifice meters using air with Reynolds number ranging from 22,000 to 200,000 . The eccentricity tests were conducted for both away from and toward the upstream tap. The experimental results show the eccentricity of the plate cause an increase in the discharge coefficient, with beta ratio of 0.2 to be quite insensitive to the effect. While comparing their results with the ISO 5167 standards for eccentricity effect, they suggested that there is substantial scope for relaxing the eccentricity limit from the standards to the benefit of users without substantially increasing uncertainty of discharge. 
They also suggested locating taps in perpendicular with the expected direction of maximum eccentricity to minimize the effect of eccentricity for orifice metering accuracy.

Nemitallah et al. (2014) performed CFD simulations to study the effect of solid particle erosion on the downstream of an orifice using $2 \%$ solid particle concentration with water as the particle carrying fluid for carbon steel and aluminum pipes. The rate of erosion and the erosion pattern for the downstream of orifice plate due to the solid particles are investigated through the effect of flow velocity and sand particle size. The mathematical models are based on the solution of the conservations of mass and momentum using realizable turbulence model while the particle trajectories are tracked using a Lagrangian particle-tracking model. The results display two erosion peaks in the downstream side of the orifice plat with the first peak occurs in the separation zone right after the vena contracta and the second peak forming in the reattachment region. Increase in the inlet flow velocity will cause an increase in the total erosion rate whereas an increase in particle size would result in a decrease of the total erosion rate.

\section{Parametric studies}

Sheikholeslami and Patel (1988) studied the variations in discharge coefficient as results of variation in beta ratio, Reynolds number, upstream and downstream boundary conditions, pipe surface roughness, and upstream swirl. Reynolds number of $4 \times 10^{4}, 4 \times 10^{5}, 4 \times 10^{6}, 4 \times 10^{7}$, and $4 \times 10^{8}$ are studied for beta ratios of 0.4 and 0.75 by changing the fluid properties. The numerical results are all within $2 \%$ of the empirical values from the standards and shown smaller variations for the changes in discharge coefficient. The results displayed similar trends as discharge coefficients increase with decreasing Reynolds number. Beta ratios of 0.4, 0.6 and 0.75 are studied for the effect of beta ratio at Reynolds number of $4 \times 10^{4}$ and $4 \times 10^{6}$. The overall trends for the variation of the discharge coefficients with beta ratio followed well with the empirical data. The effect for pipe surface roughness is less than $0.7 \%$ of maximum increase for the discharge coefficient for roughness heights up to $500 \mu \mathrm{m}$. The effect of upstream and downstream boundary conditions is studied with partially open valve, reducer, and expander for beta ratio of 0.4 with Reynolds number of $4 \times 10^{6}$. The effect of downstream boundary condition is insignificant to the discharge coefficient from the model while the upstream flowing boundary conditions can affect the discharge coefficient significantly. Shan et al. (2016) studied the effects of the beta ratio on the flow field employing a planar particle image velocimetry measuring technique. The experiment was conducted through a 1.811 inch pipe for beta ratios of $0.41,0.5$, and 0.62 with a Reynolds number of 25,000 . The experiment results display a slight beta ratio dependence for
Table 2 Data for base case $(100,712,472)$

\begin{tabular}{ll}
\hline Differential pressure in inch of water (inch) & 144.36 \\
\hline Flowing pressure (psia) & 1197.03 \\
Flow temperature $\left({ }^{\circ} \mathrm{F}\right)$ & 68.31 \\
Flow hours (hr) & 24 \\
Meter tube internal diameter (inch) & 4.026 \\
Orifice plate bore diameter (inch) & 2 \\
Real gas relative density & 0.5701 \\
Gas density (lbm/ft $\left.{ }^{3}\right)$ & 4.0882 \\
Gas density $(\mathrm{lbm} / \mathrm{gal})$ & 0.5465 \\
Gas viscosity (cp) & 0.0132 \\
Reynolds number & $3,136,516.29$ \\
Gas volume (Mcf/hr) & 496.43 \\
Gas volume (Mcf/Day) & $11,914.37$ \\
\hline
\end{tabular}

Table 3 Relationship of metering parameters and gas volume

\begin{tabular}{ll}
\hline Metering parameters & $\begin{array}{l}\text { Gas volume } \\
\text { calculation, } \\
\mathrm{Q}_{\mathrm{v}}\end{array}$ \\
\hline Differential pressure, $h_{\mathrm{w}}$, inch & $\uparrow$ \\
Flowing pressure, $p_{\mathrm{f} 1}$, psia & $\uparrow$ \\
Orifice plate bore diameter, $d$, inch & $\uparrow$ \\
Meter tube internal diameter, $D$, inch & $\downarrow$ \\
Flowing temperature, $T_{\mathrm{f}},{ }^{\circ} \mathrm{R}$ & $\downarrow$ \\
Real gas relative density, $G_{\mathrm{r}}$ & $\downarrow$ \\
Flow hour, hr & $\uparrow$ \\
Base pressure, $p_{\mathrm{b}}$, psia & $\downarrow$ \\
Base temperature, $T_{\mathrm{b}},{ }^{\circ} \mathrm{R}$ & $\uparrow$ \\
Compressibility at base conditions, $Z_{\mathrm{b}}$ & $\uparrow$ \\
Compressibility at flowing conditions, $Z_{\mathrm{f} 1}$ & $\downarrow$ \\
\hline
\end{tabular}

the location of the vena contracta. The effect of beta ratios is insignificant for the lengths of the primary and secondary recirculation regions. However, as flow progress downstream, the wall effects showed strong beta ratios as shear layer develop.

We also compared with the experimental data from the National Institute of Standards and Technology (Whetstone et al., 1988) for the validation of the codes. For the 6 inch meter tube inner diameter, we validated over the beta ratios of $0.20618,0.37125$, and 0.57724 ; for the 10 inch meter tube inner diameter, we validated over the beta ratios of 0.37405 , 0.49876 , and 0.57373 . For the 116 cases we have validated, the flowrates for all of the cases are within $1 \%$ of the experimental data using the reference gas composition.

To perform the sensitivity analysis for the gas volume and coefficients to the measuring parameters of the Orifice meter, the following base case presented in Table 2 is used to 
perform the calculations with the codes we have developed based on the gas volume calculation equations.

For the parameters of differential pressure, flowing pressure, flowing temperature, the study is conducted by keeping the other parameters constant while running the calculations through the studied parameter from $-100 \%$ to $+100 \%$ of the base case. For the other parameters, similar approach is conducted but the ranges are limited due to the physicality of the orifice meter setup and other factors.

After the calculations over the selected range for each of the parameters, Table 3 provides an overview of how each metering parameter affects the gas volume calculations. An arrow $\uparrow$ indicates that gas volume is larger with the increased metering parameter, for example that a higher than actual flowing pressure $\mathrm{p}_{\mathrm{f} 1}$ measured/reported at the meter would results into a larger than actual gas volume. For parameter flow hours, it follows strictly a linear relationship with gas volume, but flow hours should be recorded precisely as it can cause significant inaccuracy if not recorded correctly. Table 4 provides an overview how each of the coefficients is affected by metering parameter(s). An arrow $\uparrow$ indicates that a coefficient is larger with the increased metering parameter, for example that a higher than actual flowing pressure $P_{\mathrm{f} 1}$ measured/reported at the meter would results into a larger than actual expansion factor $Y_{1}$. In terms of volume calculations, the numeric conversion factor has a significant impact,

Table 4 Relationship of metering parameters and coefficients

\begin{tabular}{|c|c|c|c|c|c|c|c|c|c|}
\hline \multirow{2}{*}{$\begin{array}{l}\text { Metering } \\
\text { parameters }\end{array}$} & \multicolumn{9}{|l|}{ Coefficients } \\
\hline & $\begin{array}{l}\text { Numeric } \\
\text { conversion } \\
\text { factor, } F_{\mathrm{n}}\end{array}$ & $\begin{array}{l}\text { Orifice } \\
\text { calculation } \\
\text { factor, } F_{\mathrm{c}}\end{array}$ & $\begin{array}{l}\text { Orifice } \\
\text { slope fac- } \\
\text { tor, } F_{\mathrm{sl}}\end{array}$ & $\begin{array}{l}\text { Expansion } \\
\text { factor, } Y_{1}\end{array}$ & $\begin{array}{l}\text { Base pres- } \\
\text { sure factor, } \\
F_{\mathrm{pb}}\end{array}$ & $\begin{array}{l}\text { Base } \\
\text { temperature } \\
\text { factor, } F_{\mathrm{tb}}\end{array}$ & $\begin{array}{l}\text { Flowing } \\
\text { temperature } \\
\text { factor, } F_{\mathrm{tf}}\end{array}$ & $\begin{array}{l}\text { Real gas rela- } \\
\text { tive density } \\
\text { factor, } F_{\mathrm{gr}}\end{array}$ & $\begin{array}{l}\text { Super-com- } \\
\text { pressibility } \\
\text { factor, } F_{\mathrm{pv}}\end{array}$ \\
\hline $\begin{array}{l}\text { Differential } \\
\text { pressure, } \\
h_{\mathrm{w}}, \text { inch }\end{array}$ & & & & $\downarrow$ & & & & & \\
\hline $\begin{array}{l}\text { Flowing } \\
\text { pressure, } \\
p_{\mathrm{fl}}, \text { psia }\end{array}$ & & & & $\uparrow$ & & & & & \\
\hline $\begin{array}{l}\text { Orifice } \\
\text { plate bore } \\
\text { diameter, } d \text {, } \\
\text { inch }\end{array}$ & $\uparrow$ & $\uparrow$ & $\uparrow$ & $\downarrow$ & & & & & \\
\hline $\begin{array}{l}\text { Meter tube } \\
\text { internal } \\
\text { diameter, } \\
D, \text { inch }\end{array}$ & $\downarrow$ & $\downarrow$ & $\downarrow$ & $\uparrow$ & & & & & \\
\hline $\begin{array}{l}\text { Base pres- } \\
\text { sure, } p_{\mathrm{b}}, \\
\text { psia }\end{array}$ & & & & & $\downarrow$ & & & & \\
\hline $\begin{array}{c}\text { Base tem- } \\
\text { perature, } \\
T_{\mathrm{b}},{ }^{\circ} \mathrm{R}\end{array}$ & & & & & & $\uparrow$ & & & \\
\hline $\begin{array}{l}\text { Flowing tem- } \\
\text { perature, } \\
T_{\mathrm{f}},{ }^{\circ} \mathrm{R}\end{array}$ & & & & & & & $\downarrow$ & & \\
\hline $\begin{array}{l}\text { Real gas rela- } \\
\text { tive density, } \\
G_{\mathrm{r}}\end{array}$ & & & $\downarrow$ & & & & & $\downarrow$ & $\uparrow$ \\
\hline $\begin{array}{l}\text { Compress- } \\
\text { ibility at } \\
\text { base condi- } \\
\text { tions, } \mathrm{Z}_{\mathrm{b}}\end{array}$ & & & & & & & & & $\uparrow$ \\
\hline $\begin{array}{l}\text { Compress- } \\
\text { ibility at } \\
\text { flowing } \\
\text { conditions, } \\
Z_{\mathrm{f} 1}\end{array}$ & & & & & & & & & $\downarrow$ \\
\hline $\begin{array}{c}\text { Reynolds } \\
\text { number }\end{array}$ & & $\uparrow$ & $\downarrow$ & $\uparrow$ & & & & & \\
\hline
\end{tabular}


which is affected by the orifice plate bore diameter and the meter tube internal diameter.

The plots for the sensitivity of gas volume to the parameters are shown in "Appendix A". The sensitivity of gas volume to the parameter of differential pressure in inch of water is shown in Fig. 17. Gas volume increases as differential pressure in inch of water increases and vice versa. As differential pressure in inch of water decreases by $10 \%$ from the base case, gas volume is decreased by $5.11 \%$; as differential pressure in inch of water increases by $10 \%$ from the base case, gas volume is increased by $4.86 \%$. As for the coefficients, changes in differential pressure will have its effect on the expansion factor and the sensitivity is shown in Fig. 23. Expansion factor decreases as differential pressure in inch of water increases and vice versa. As differential pressure in inch of water decreases by $10 \%$ from the base case, expansion factor is increased by $0.02 \%$; as differential pressure in inch of water increases by $10 \%$ from the base case, expansion factor is decreased by $0.02 \%$.

The sensitivity of gas volume to the parameter of flowing pressure is shown in Fig. 18. Gas volume increases as flowing pressure increases and vice versa. As flowing pressure decreases by $10 \%$ from the base case, gas volume is decreased by $5.83 \%$; as flowing pressure increases by $10 \%$ from the base case, gas volume is increased by $5.62 \%$. As for the coefficients, changes in flowing pressure will have its effect on the expansion factor and the sensitivity is shown in Fig. 24. Expansion factor increases as flowing pressure increases and vice versa. As flowing pressure decreases by $10 \%$ from the base case, expansion factor is decreased by $0.02 \%$; as flowing pressure increases by $10 \%$ from the base case, expansion factor is increased by $0.02 \%$.

The sensitivity of gas volume to the parameter of flowing temperature is shown in Fig. 19. Gas volume decreases as flowing temperature increases and vice versa. As flowing temperature decreases by $10 \%$ from the base case, gas volume is increased by $1.12 \%$; as flowing temperature increases by $10 \%$ from the base case, gas volume is decreased by $1.05 \%$. As for the coefficients, changes in flowing temperature will have its effect on the flowing temperature factor and the sensitivity is shown in Fig. 25. Flowing temperature factor decreases as flowing temperature increases and vice versa. As flowing temperature decreases by $10 \%$ from the base case, flowing temperature factor is increased by $0.45 \%$; as flowing temperature increases by $10 \%$ from the base case, flowing temperature factor is decreased by $0.44 \%$.

The sensitivity of gas volume to the parameter of meter tube internal diameter is shown in Fig. 20. Gas volume decreases as meter tube internal diameter increases and vice versa. As meter tube internal diameter decreases by $10 \%$, gas volume is increased by $1.97 \%$; as meter tube internal diameter increases by $10 \%$, gas volume is decreased by $1.19 \%$. As for the coefficients, changes in meter tube internal diameter will have its effect on the numeric conversion factor, Orifice calculation factor, Orifice slope factor, and expansion factor. The sensitivity for the numeric conversion factor is shown in Fig. 26 and numeric conversion factor decreases as meter tube internal diameter increases and vice versa. As meter tube internal diameter decreases by $10 \%$, numeric conversion factor is increased by $1.74 \%$.; as meter tube internal diameter increases by $10 \%$, numeric conversion factor is decreased by $1.01 \%$. The sensitivity for the Orifice calculation factor is shown in Fig. 27 and Orifice calculation factor decreases as meter tube internal diameter increases and vice versa. As meter tube internal diameter decreases by $10 \%$, Orifice calculation factor is increased by $0.17 \%$; as meter tube internal diameter increases by $10 \%$, Orifice calculation factor is decreased by $0.15 \%$. The sensitivity for the Orifice slope factor is shown in Fig. 28 and Orifice slope factor decreases as meter tube internal diameter increases and vice versa. As meter tube internal diameter decreases by $10 \%$, Orifice slope factor is increased by $42.25 \%$; ; as meter tube internal diameter increases by $10 \%$, Orifice slope factor is decreased by $25.83 \%$. The sensitivity for the expansion factor is shown in Fig. 29 and expansion factor increases as meter tube internal diameter increases and vice versa. As meter tube internal diameter decreases by $10 \%$, expansion factor is decreased by $0.005 \%$; ; as meter tube internal diameter increases by $10 \%$, expansion factor is increased by $0.003 \%$.

The sensitivity of gas volume to the parameter of Orifice plate bore diameter is shown in Fig. 21. Gas volume increases as Orifice plate bore diameter increases and vice versa. As Orifice plate bore diameter decreases by $10 \%$, gas volume is decreased by $20.05 \%$; as Orifice plate bore diameter increases by $10 \%$, gas volume is increased by $23.10 \%$. As for the coefficients, changes in Orifice plate bore diameter will have its effect on the numeric conversion factor, Orifice calculation factor, Orifice slope factor, and expansion factor. The sensitivity for the numeric conversion factor is shown in Fig. 30 and numeric conversion factor increases as Orifice plate bore diameter increases and vice versa. As Orifice plate bore diameter decreases by $10 \%$, numeric conversion factor is decreased by $19.89 \%$; as Orifice plate bore diameter increases by $10 \%$, numeric conversion factor is increased by $22.86 \%$. The sensitivity for the Orifice calculation factor is shown in Fig. 31 and Orifice calculation factor increases as Orifice plate bore diameter increases and vice versa. As Orifice plate bore diameter decreases by $10 \%$, Orifice calculation factor is decreased by $0.18 \%$; as Orifice plate bore diameter increases by $10 \%$, Orifice calculation factor is increased by $0.15 \%$. The sensitivity for the Orifice slope factor is shown in Fig. 32 and Orifice slope factor increases as Orifice plate bore diameter increases and vice versa. As Orifice plate bore diameter decreases by $10 \%$, Orifice slope factor is decreased by $-24.63 \%$; as Orifice plate bore

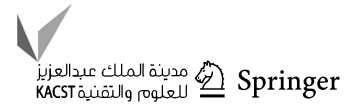


diameter increases by $10 \%$, Orifice slope factor is increased by $32.37 \%$. The sensitivity for the expansion factor is shown in Fig. 33 and expansion factor decreases as Orifice plate bore diameter increases and vice versa. As Orifice plate bore diameter decreases by $10 \%$, expansion factor is increased by $0.003 \%$; as Orifice plate bore diameter increases by $10 \%$, expansion factor is decreased by $0.004 \%$.

The sensitivity of gas volume to the parameter of real gas relative density is shown in Fig. 22. Gas volume decreases as meter tube internal diameter increases and vice versa. As meter tube internal diameter decreases by $10 \%$, gas volume is increased by $3.91 \%$; as meter tube internal diameter increases by $10 \%$, gas volume is decreased by $3.06 \%$. As for the coefficients, changes in real gas relative density will have its effect on the Orifice slope factor, real gas relative density factor, and supercompressibility factor. The sensitivity for the Orifice slope factor is shown in Fig. 34 and Orifice slope factor decreases as real gas relative density increases and vice versa. As real gas relative density decreases by $10 \%$, Orifice slope factor is increased by $2.80 \%$; as real gas relative density increases by $10 \%$, Orifice slope factor is decreased by $2.61 \%$. The sensitivity for the real gas relative density factor is shown in Fig. 35 and real gas relative density factor decreases as real gas relative density increases and vice versa. As real gas relative density decreases by $10 \%$ from the base case, real gas relative density factor is increased by $5.41 \%$; as real gas relative density increases by $10 \%$ from the base case, real gas relative density factor is decreased by $4.65 \%$. The sensitivity for the supercompressibility factor is shown in Fig. 36 and supercompressibility factor increases as real gas relative density increases and vice versa. As real gas relative density decreases by $10 \%$ from the base case, supercompressibility factor is decreased by $1.43 \%$; real gas relative density increases by $10 \%$ from the base case, supercompressibility factor is increased by $1.68 \%$.

One of the fluid and flowing conditions for measuring using Orifice meter set by AGA is that the Reynolds number has to be greater than 4,000 . Fluid behavior between a Reynolds number of 2,000 and 4,000 is difficult to predict and for Reynolds number below 2,000 the flow becomes laminar flow. Since Eqs. 10 and 11 are developed using Reynolds number greater than 4,000, for any Reynolds number below that limit, the standard empirical equations of coefficients of discharge will not be valid to the same tolerance.

Reynolds number is calculated based on an iterative scheme using Eq. 42, starting with an assumed coefficient of discharge of 0.6. Gas volume decreases as Reynolds number increases and vice versa as in Fig. 37. As Reynolds number decreases by $10 \%$, gas volume is increased by $0.006 \%$; as Reynolds number increases by $10 \%$, gas volume is decreased by $0.007 \%$. For the base case, the
Table 5 Rankings of the parameters to the changes in gas volume

\begin{tabular}{lc}
\hline $10 \%$ change of orifice meter parameter & $\begin{array}{l}\text { Percentage of } \\
\text { change of gas } \\
\text { volume }\end{array}$ \\
\hline Orifice plate bore diameter & 23.10 \\
Flowing pressure & 5.62 \\
Differential pressure in inch of water & 4.86 \\
Flowing temperature & -1.05 \\
Meter tube internal diameter & -1.19 \\
Real gas relative density & -3.06 \\
\hline
\end{tabular}

Table 6 Rankings of the parameters to the changes in gas volume

\begin{tabular}{lc}
\hline$-10 \%$ change of orifice meter parameter & $\begin{array}{l}\text { Percentage of } \\
\text { change of gas } \\
\text { volume }\end{array}$ \\
\hline Real gas relative density & 3.91 \\
Meter tube internal diameter & 1.97 \\
Flowing temperature & 1.12 \\
Differential pressure in inch of water & -5.11 \\
Flowing pressure & -5.83 \\
Orifice plate bore diameter & -20.05 \\
\hline
\end{tabular}

lowest threshold for the gas flow rate would be $0.60 \mathrm{Mcf} / \mathrm{hr}$ and 14.40 Mcf/Day for Reynolds number of 4000. For the normal operating flow range of gases, the Reynolds numbers are orders of magnitude higher than this low limit of 4000 and can easily surpass well above this requirement. Also, for high Reynolds number, the effect of viscosity is negligible and the viscosity variation can be ignored. Viscosity of the flowing gas will still be monitored in our calculations in cases of any discrepancies.

$R e_{\mathrm{D}}=47.0723 \frac{Q_{\mathrm{v}} G_{\mathrm{r}}}{D}$

Reynolds Number affects the calculations of Orifice calculation factor and the Orifice slope factor, as the sum of these two factors is the coefficients of discharge. Orifice calculation factor increases as Reynolds number increases and vice versa (Fig. 38). Orifice slope factor decreases as Reynolds number increases and vice versa (Fig. 39). Coefficients of discharge decreases as Reynolds number increases and vice versa (Fig. 40) due to the larger magnitude of change of the Orifice slope factor compared to the magnitude of change of the Orifice calculation factor. As Reynolds number decreases by $10 \%$, coefficients of discharge are increased by $0.006 \%$; as Reynolds number increases by $10 \%$, coefficients of discharge are decreased by $0.007 \%$. The relationship is also observed in Table 4 . The coefficients 
of discharge approach a constant as the Reynolds number approaches infinity as we can observe from the trends of the Fig. 40, as Reynolds number gets larger and larger, the uncertainty of the coefficients will become more negligible especially in terms of gas volume calculations.

To summarize the sensitivity of gas volume with respect to each of the input parameters, for every $10 \%$ of increase in Orifice meter parameters, Table 5 provides the ranking (largest to smallest) of the parameters to changes in gas volume. For every $10 \%$ of decrease in Orifice meter parameters, Table 6 provides the ranking (largest to smallest) of the parameters of changes in gas volume.

In summary, rankings of meter parameters in the order of importance are orifice plate size, flowing pressure, differential pressure in inch of water, gas composition (relative density), meter tube diameter, and then flowing temperature. Although duration of flow was not part of the sensitivity study, it is the most important one because gas volume vary linearly with flow time. This is especially important when gas flow is not continuously, such as when a plunger lift is installed. We observed that in relatively dry gas Marcellus and Utica gas wells, most wells, with the except of one operator and twelve wells out of hundreds of wells, were equipped with orifice metering and measurement.

\section{Conclusion}

To meet the needs for shale gas development and accurate measurement of high-volume gas wells, this paper provides a comprehensive and in-depth review and analysis of applicable metering and gas volume measurement technologies, including Coriolis, turbine, v-cone, and orifice meters. Conclusions include:
- For accurate orifice metering, one needs to understand and calibrate meters to eliminate effects of installation, swirl, chemical and organic contamination, physical deformation, etc.

- Out of the factors affecting Orifice metering and measurement, orifice bore diameter, flowing pressure, differential pressure, and gas composition affect measurement the most (in order of high to low impact). Flowing time is critical especially when gas flow is not continuous, such as when a plunger lift is installed.

We observed that in dry gas Marcellus and Utica gas region, most wells, with the except of one operator and twelve wells out of hundreds and thousands of wells, were equipped with orifice metering and measurement for its low cost, accuracy, and ease of calibration and maintenance. As gas flow rates drop and Reynolds number decreases, one could and should change Orifice plate size and calibrate the meter to maintain accuracy of measurement.

This article provides one with up-to-date understanding of physics and practices needed in natural gas metering and volume measurement. Meter design and measurement could be improved if the following factors could be considered: variable flow rates during the life of a shale gas well, compositional change of shale gas, and potential storage and measurement of $\mathrm{CO}_{2}, \mathrm{H}_{2}$, and $\mathrm{CH}_{4}$.

\section{Appendix A: Orifice parametric studies plots}

See Figs. 17, 18, 19, 20, 21, 22, 23, 24, 25, 26, 27, 28, 29 , $30,31,32,33,34,35,36,37,38,39$ and 40 .
Fig. 17 Change of gas volume vs. change of differential pressure in inches of water

\section{Change of Gas Volume vs. Change of Differential Pressure in inches of Water}

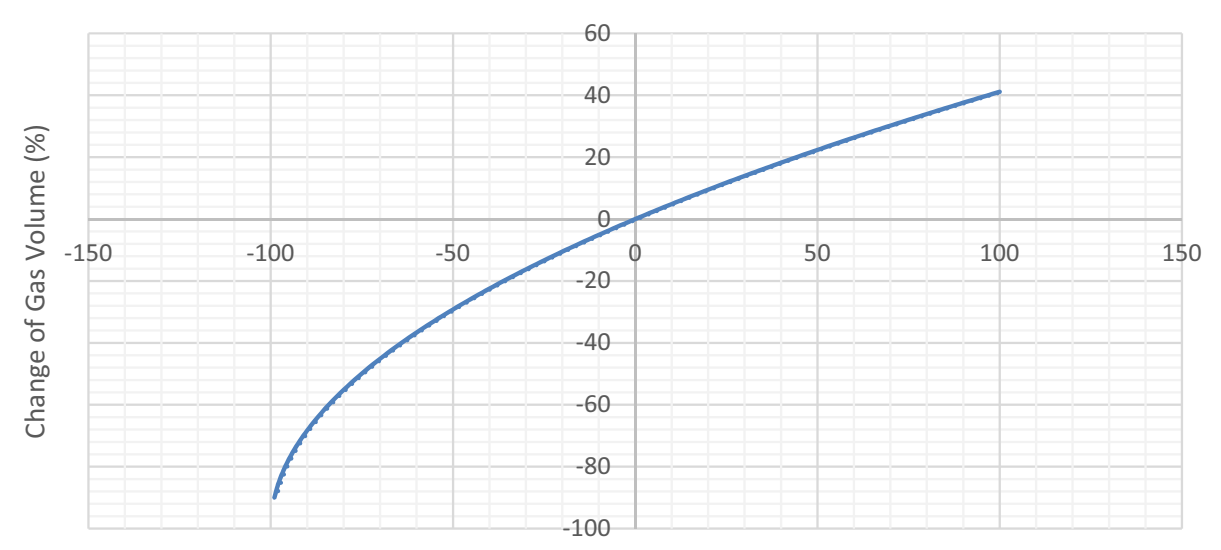

Change of Differential Pressure in inches of Water(\%) 
Fig. 18 Change of expansion factor vs. change of differential pressure in inches of water

Fig. 19 Change of gas volume vs. change of flowing pressure

Fig. 20 Change of expansion factor vs. change of flowing pressure
Change of Gas Volume vs. Change of Flowing Pressure

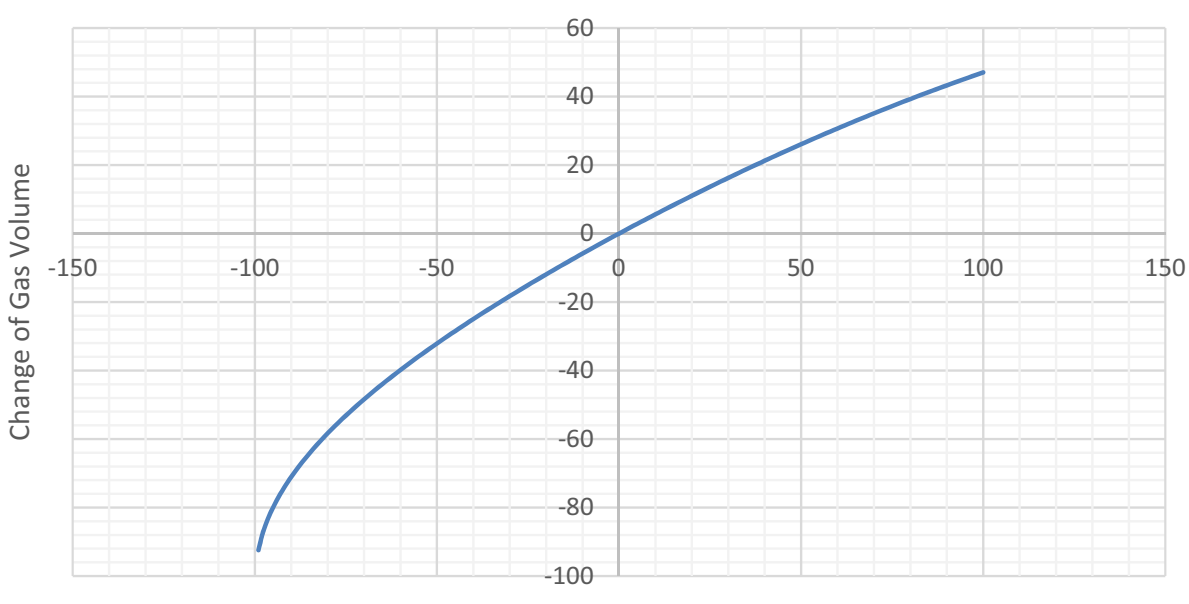

Change of Flowing Pressure

\section{Change of Gas Volume vs. Change of Flowing Temperature}

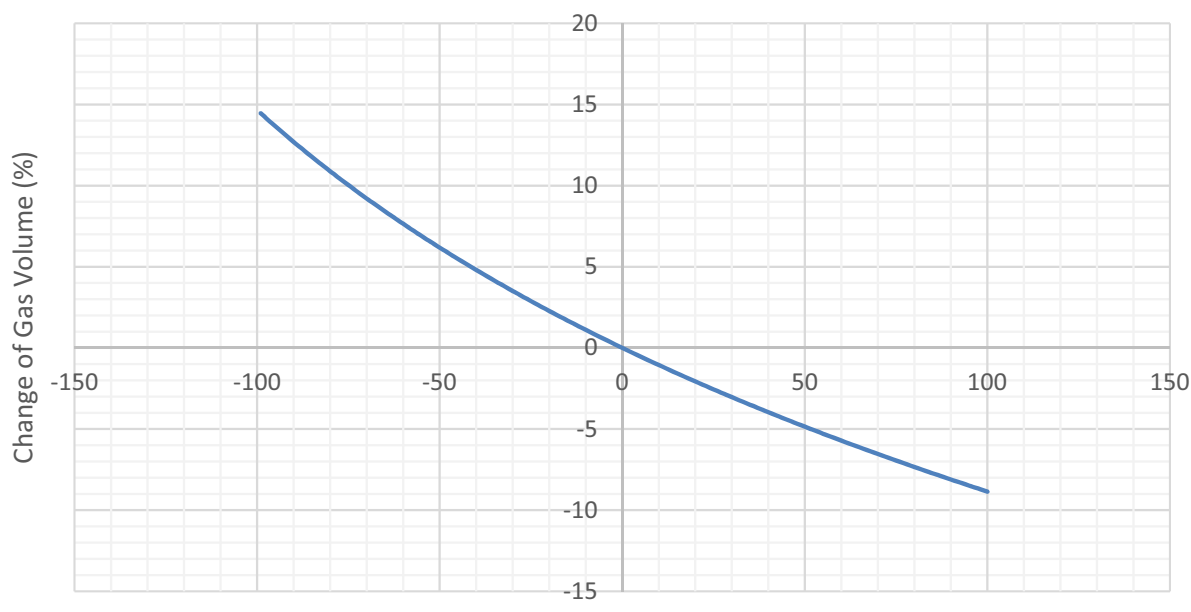

Change of Flowing Temperature (\%)

Change of Gas Volume vs. Change of Meter Tube Internal Diameter

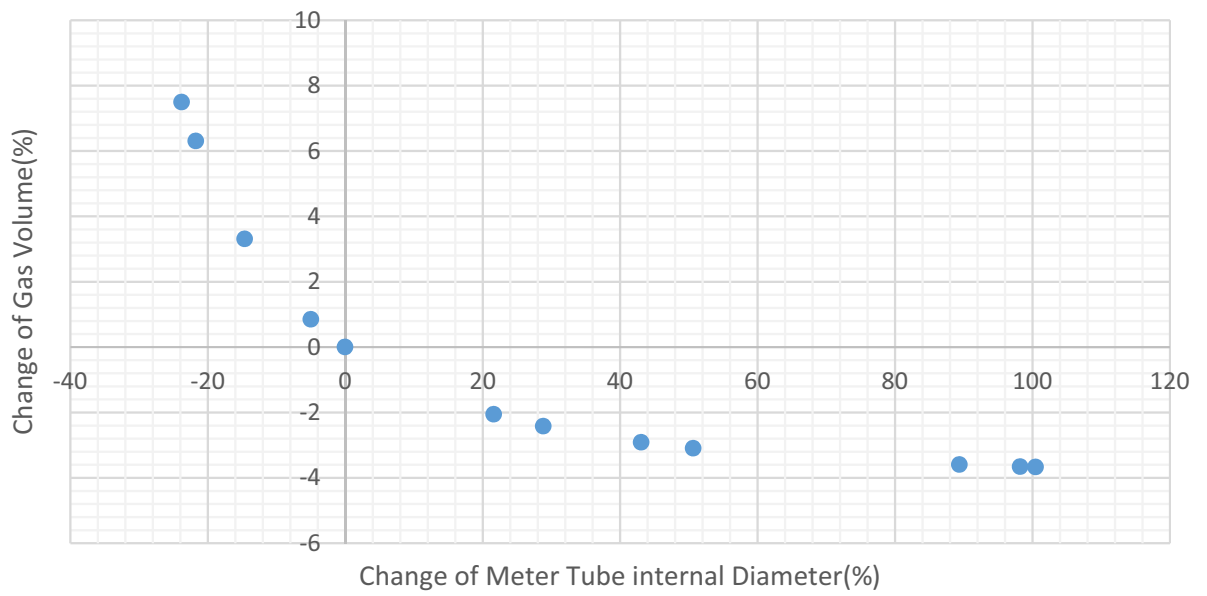


Fig. 21 Change of gas volume vs. change of flowing temperature

Fig. 22 Change of flowing temperature factor vs. change of flowing temperature

\section{Change of Gas Volume vs. Change of Orifice Plate Bore Diameter}

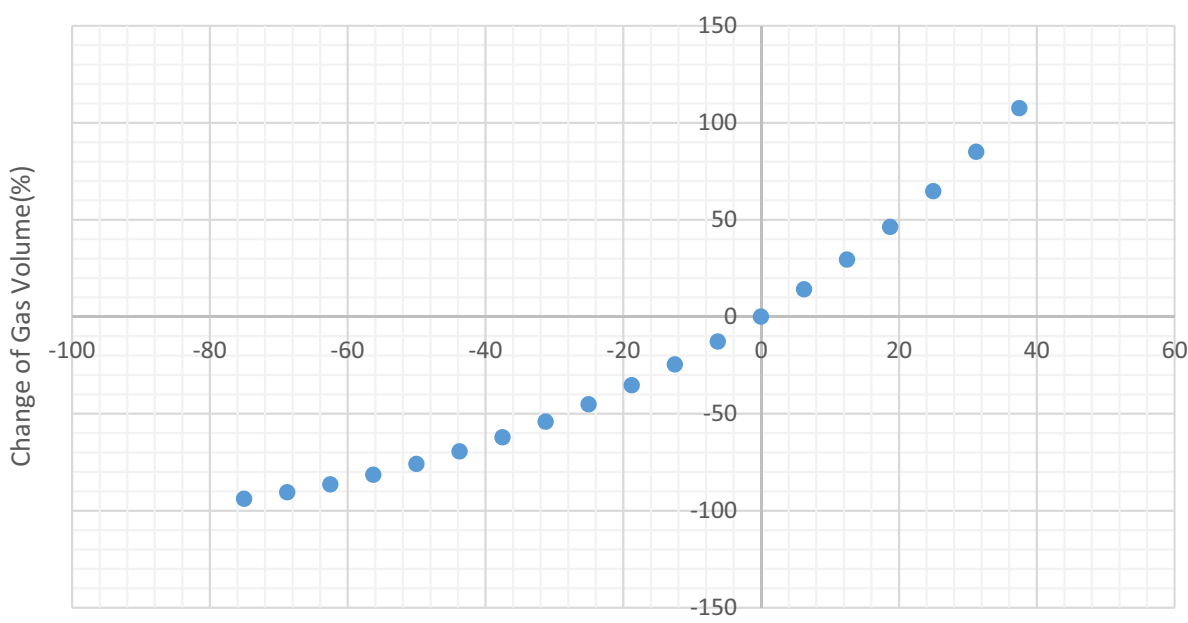

Change of Orifice Plate Bore Diameter(\%)

Change of Gas Volume vs. Change of Specific Gravity of Gas

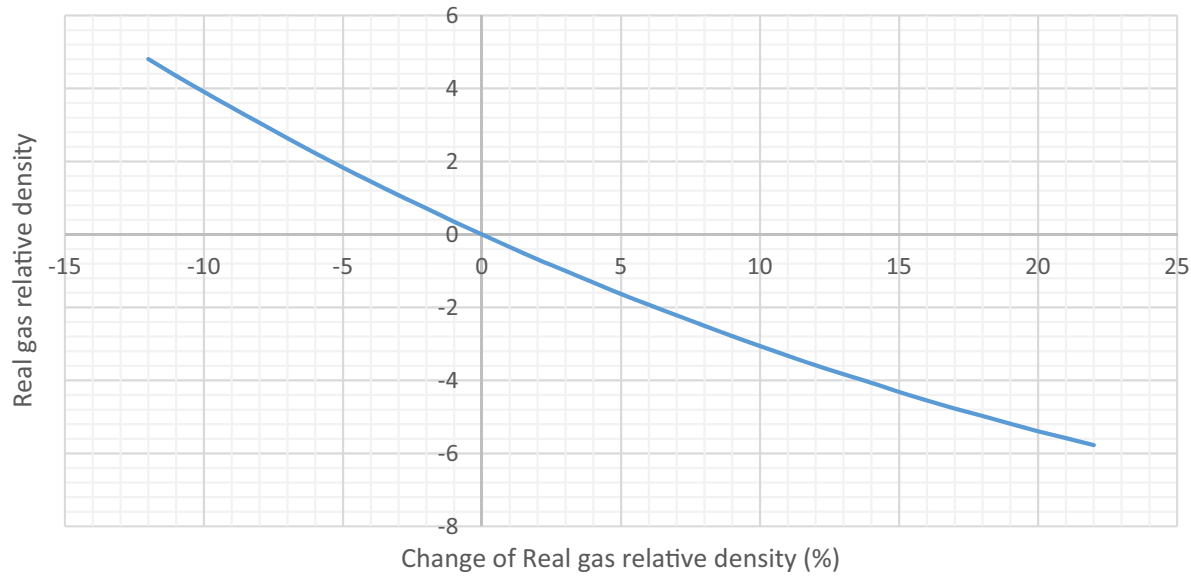

Change of Expansion Factor vs. Change of Differential Pressure in inches of Water

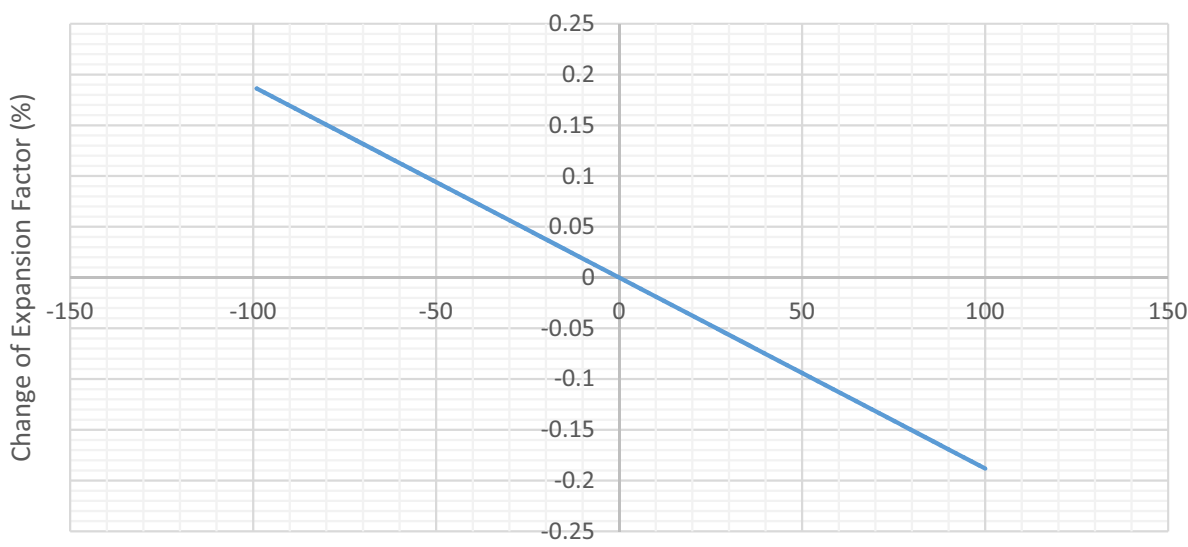

Change of Differential Pressure in inches of Water (\%)
Change of gas volume nal diameter 
Fig. 24 Change of numeric conversion factor vs. change of meter tube internal diameter

Fig. 25 Change of orifice calculation factor vs. change of meter tube internal diameter

Fig. 26 Change of orifice slope factor vs. change of meter tube internal diameter

\section{Change of Expansion Factor vs. Change of Flowing Pressure}

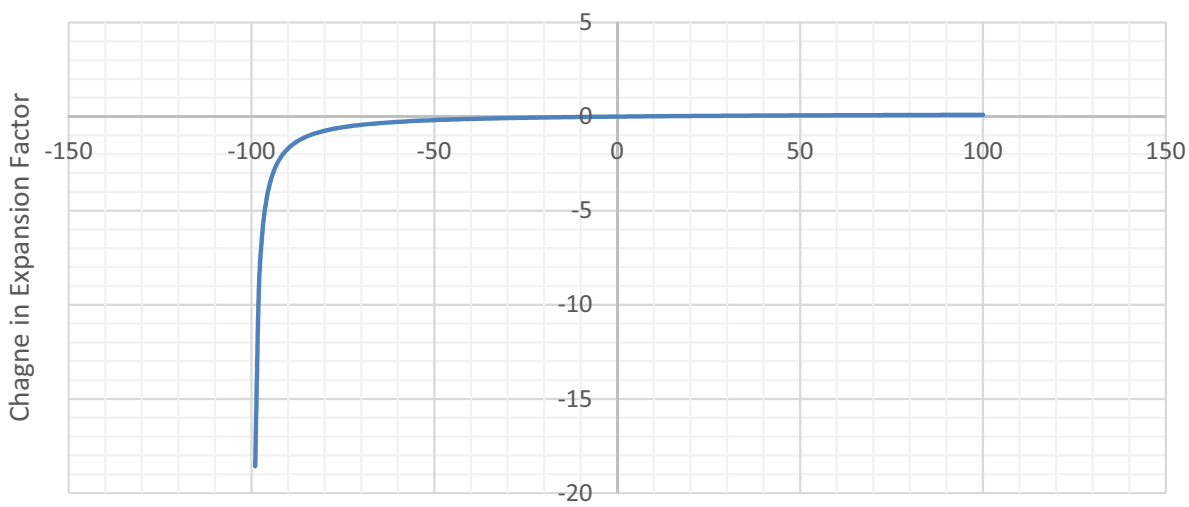

Change of Flowing Pressure

Change of Flowing Temperature Factor vs. Change of Flowing Temperature

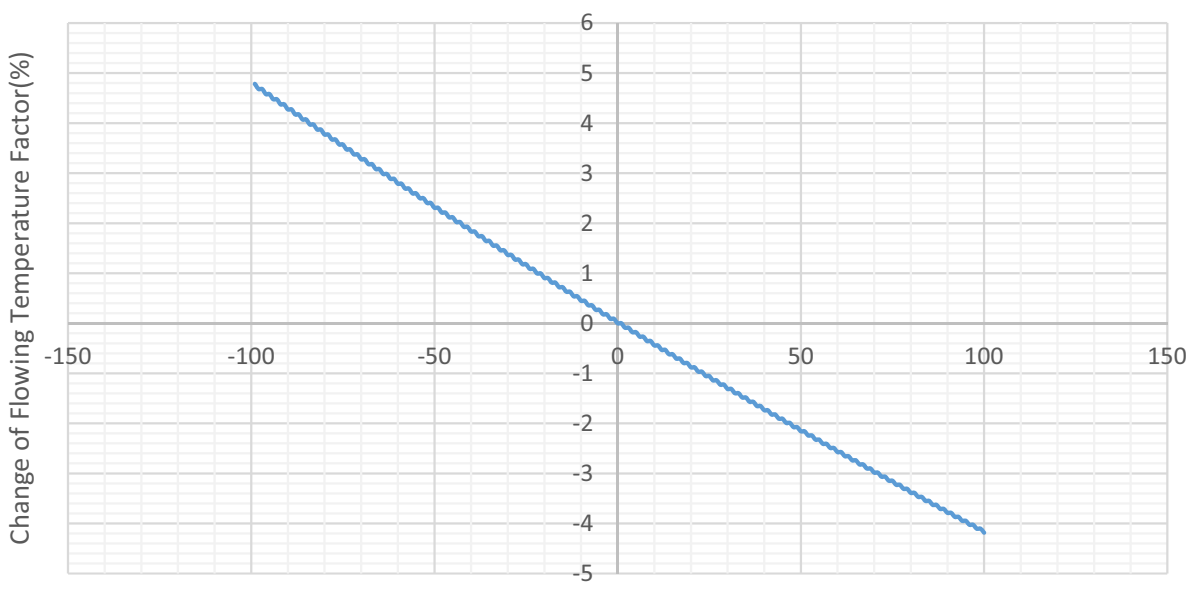

Change of Flowing Temperature(\%)

Change of Numeric Conversion Factor vs. Change of Meter Tube Internal Diameter

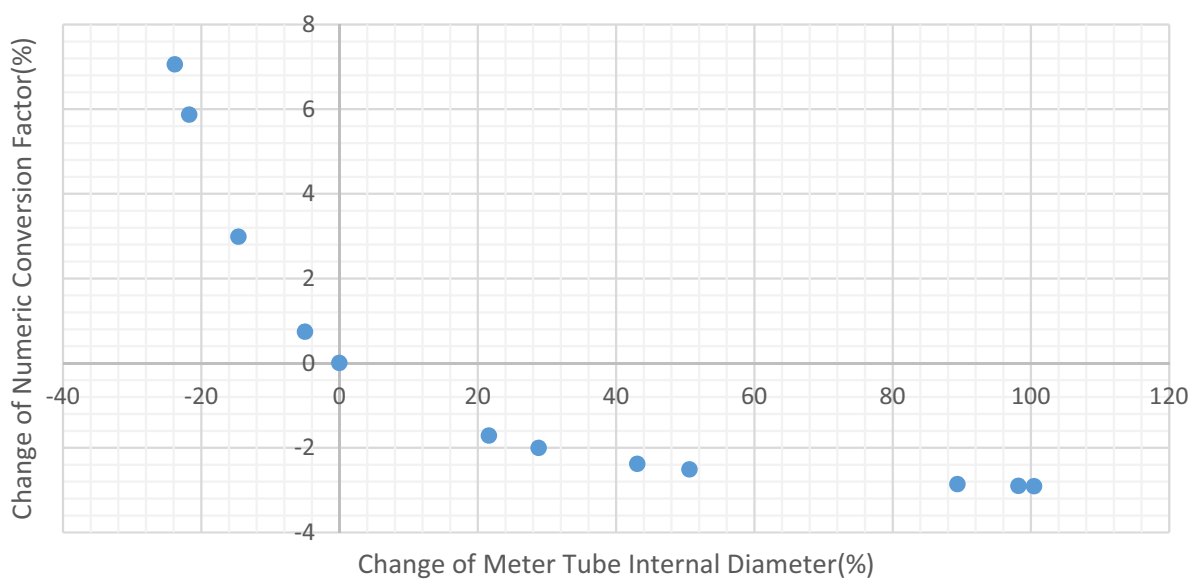


Fig. 27 Change of expansion factor vs. change of meter tube internal diameter

Fig. 28 Change of gas volume vs. change of orifice plate bore diameter
Change of Orifice Calculation Factor vs. Change of Meter Tube Internal Diameter

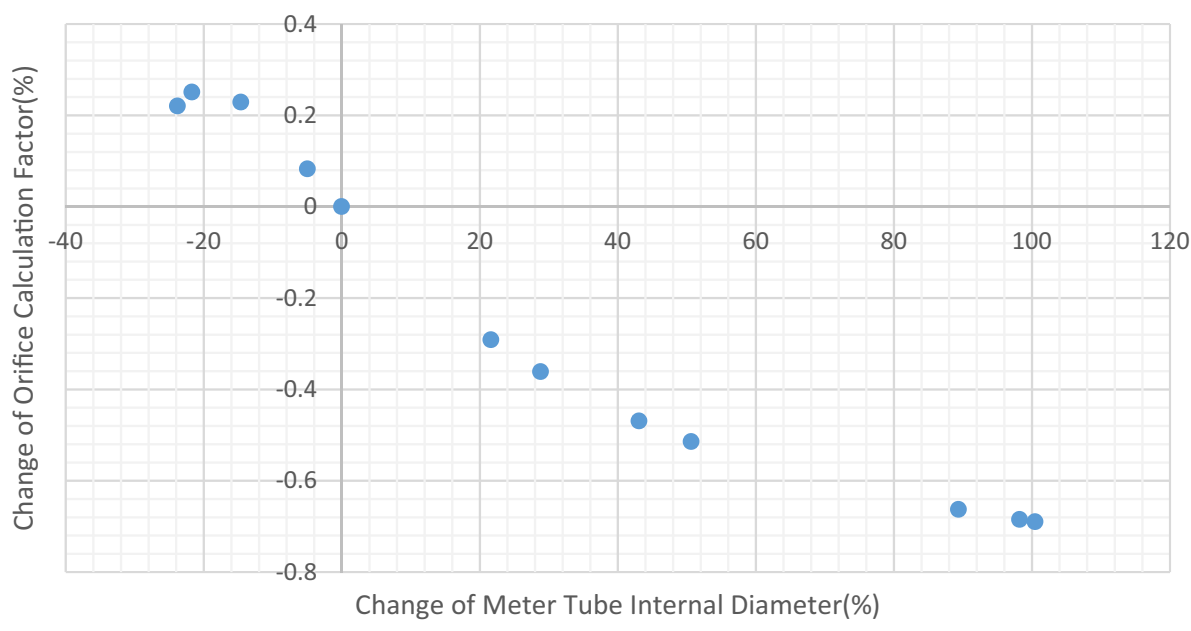

Change of Orifice Slope Factor vs. Change of Meter Tube Internal Diameter

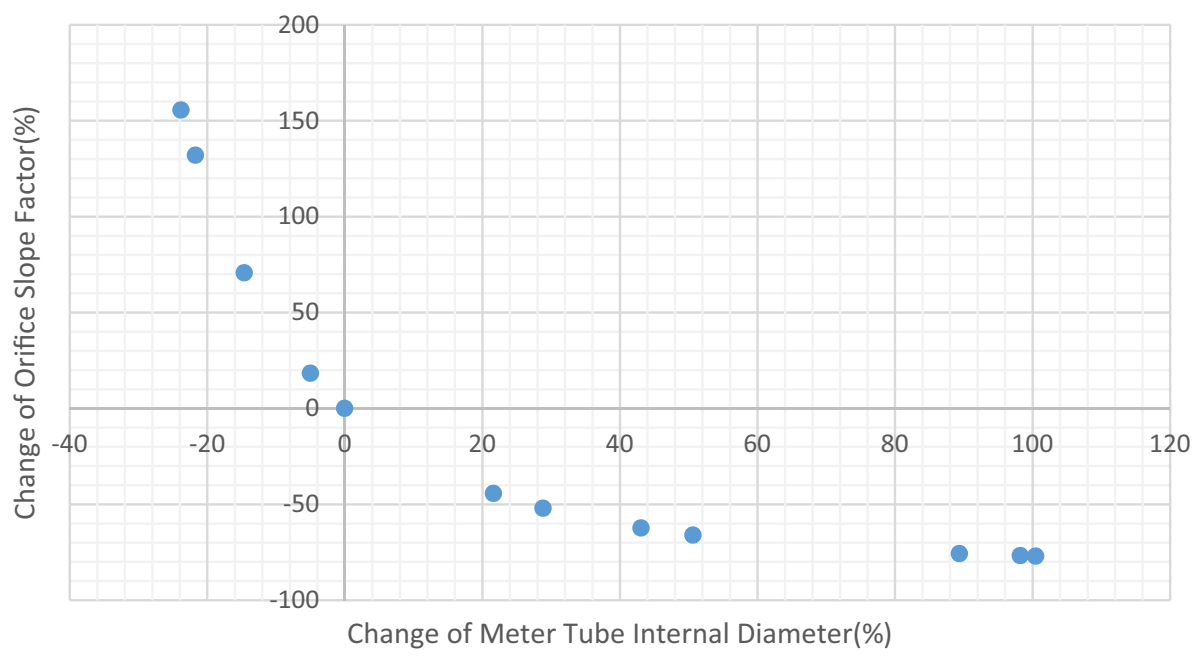


Fig. 29 Change of numeric conversion factor vs. change of orifice plate bore diameter

Fig. 30 Change of orifice calculation factor vs. change of orifice plate bore diameter

\section{Change of Expansion Factor vs. Change of Meter Tube Internal Diameter}

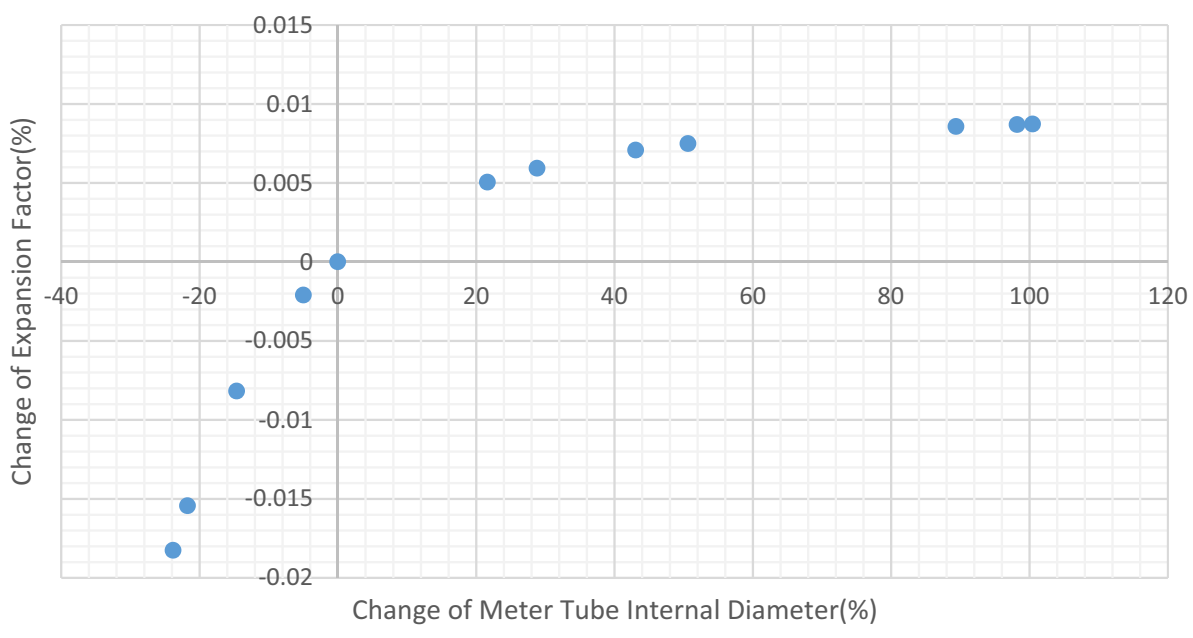

Change of Numeric Conversion Factor vs. Change of Orifice Plate Bore Diameter

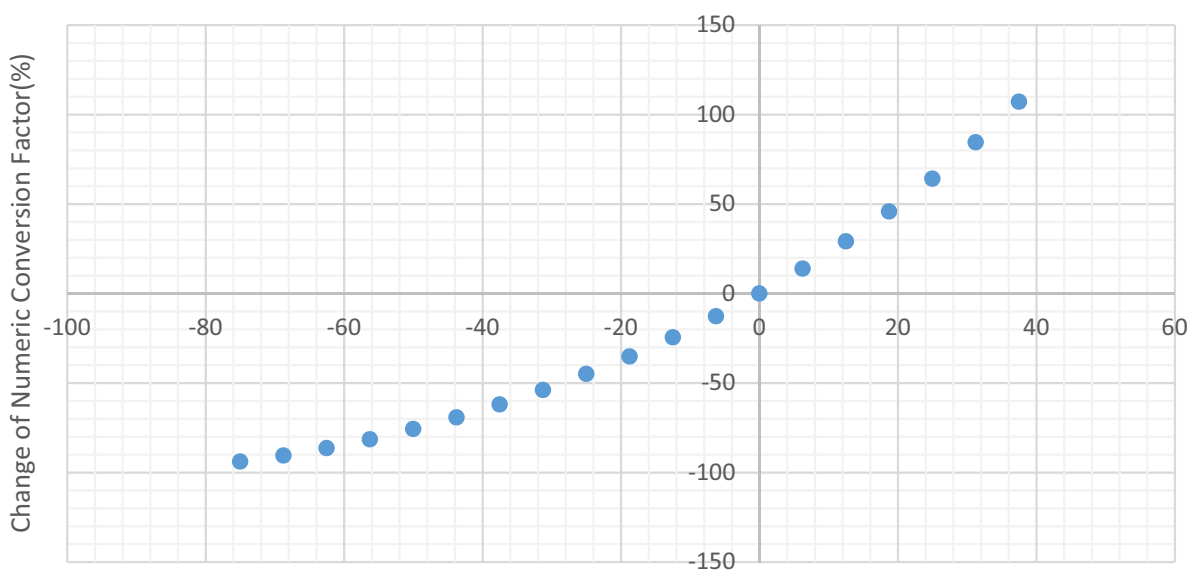

Change of Orifice Plate Bore Diameter(\%) 
Fig. 31 Change in orifice slope factor vs. change in orifice plate bore diameter

Fig. 32 Change in expansion factor vs. change in orifice plate bore diameter
Change of Orifice Calculation Factor vs. Change of Orifice Plate Bore Diameter

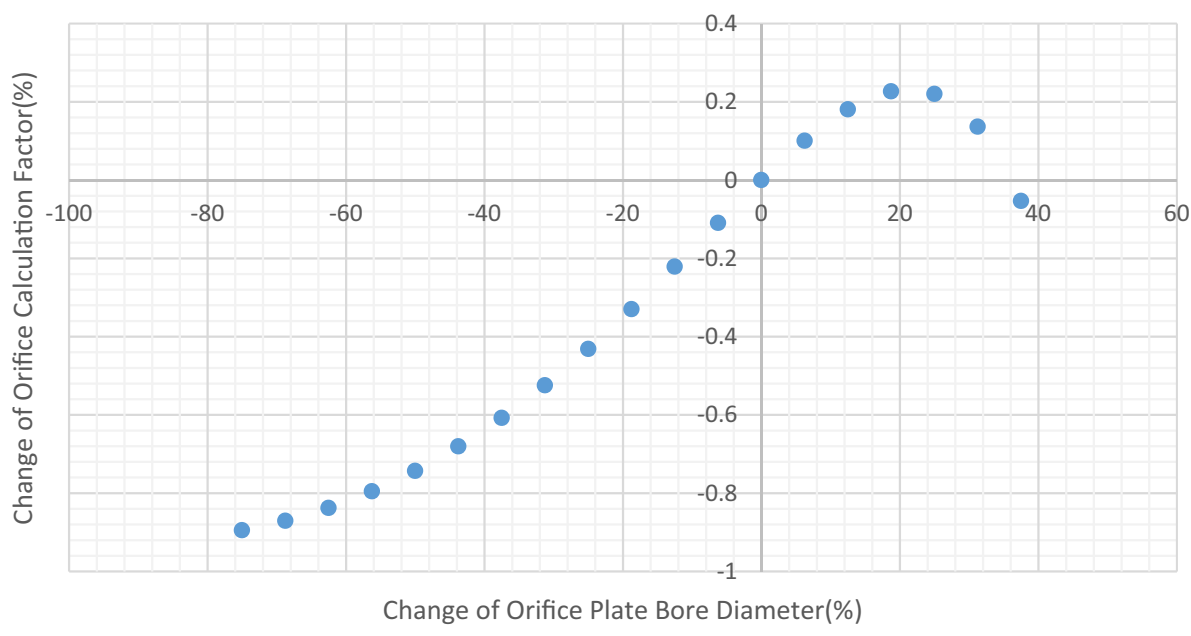

Change in Orifice Slope Factor vs. Change in Orifice Plate Bore Diameter

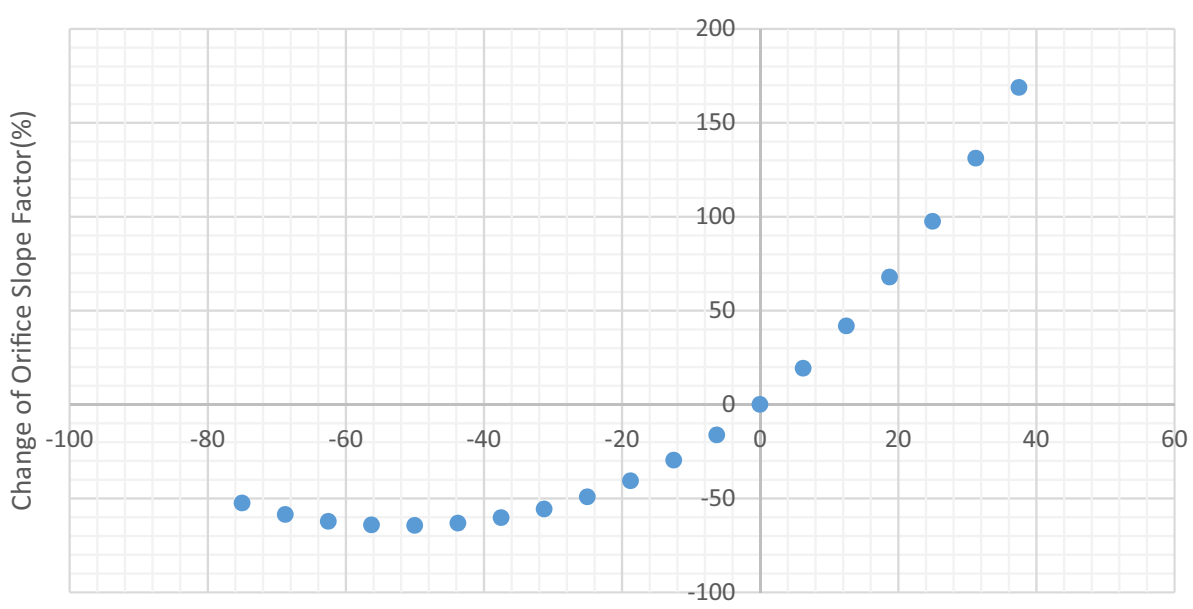

Change of Orifice Plate Bore Diameter (\%) 
Fig. 33 Change of gas volume vs. change of specific gravity of gas

Fig. 34 Change of orifice slope factor vs. change of specific gravity of gas

\section{Change in Expansion Factor vs. Change in Orifice Plate Bore Diameter}

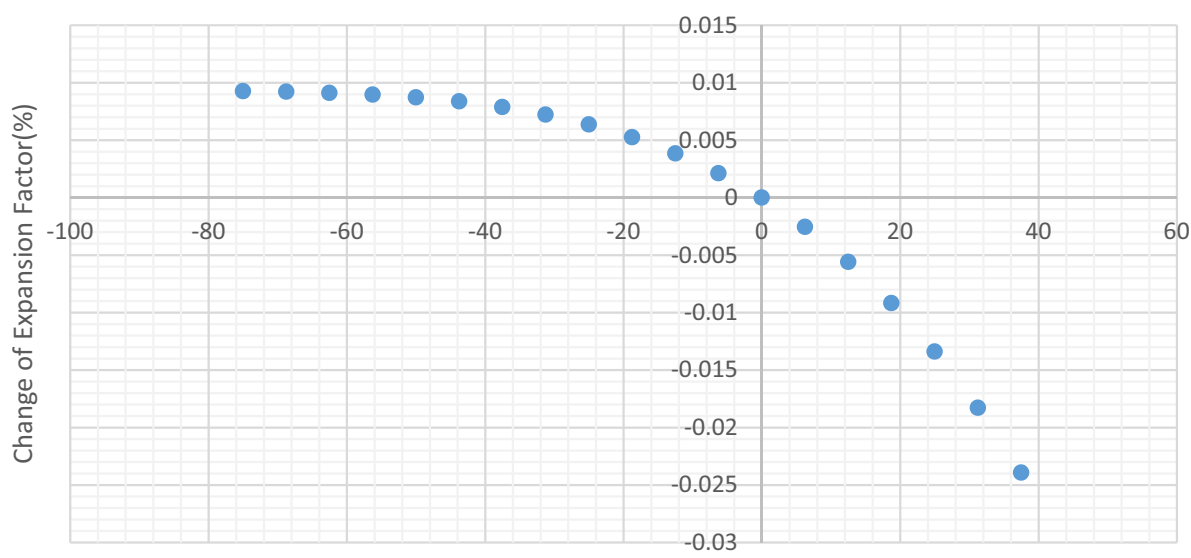

Change of Orifice Plate Bore Diameter(\%)

Change of Orifice Slope Factor vs. Change of Specific Gravity of Gas

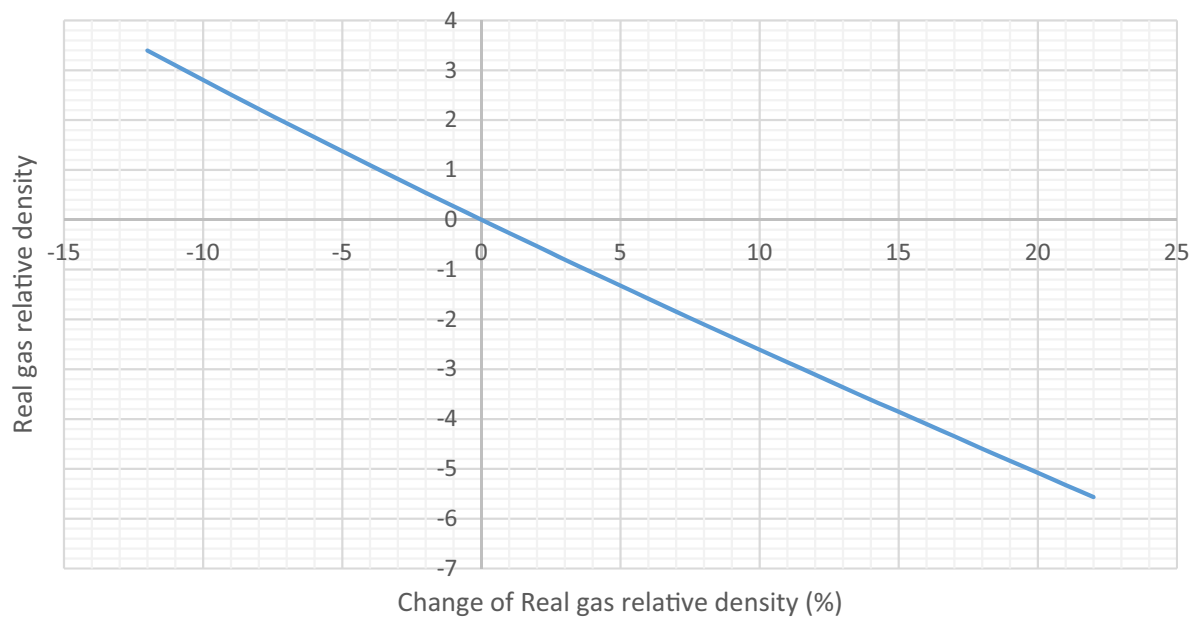

Change of Real Gas Relative Density Factor vs. Change of Real gas relative density

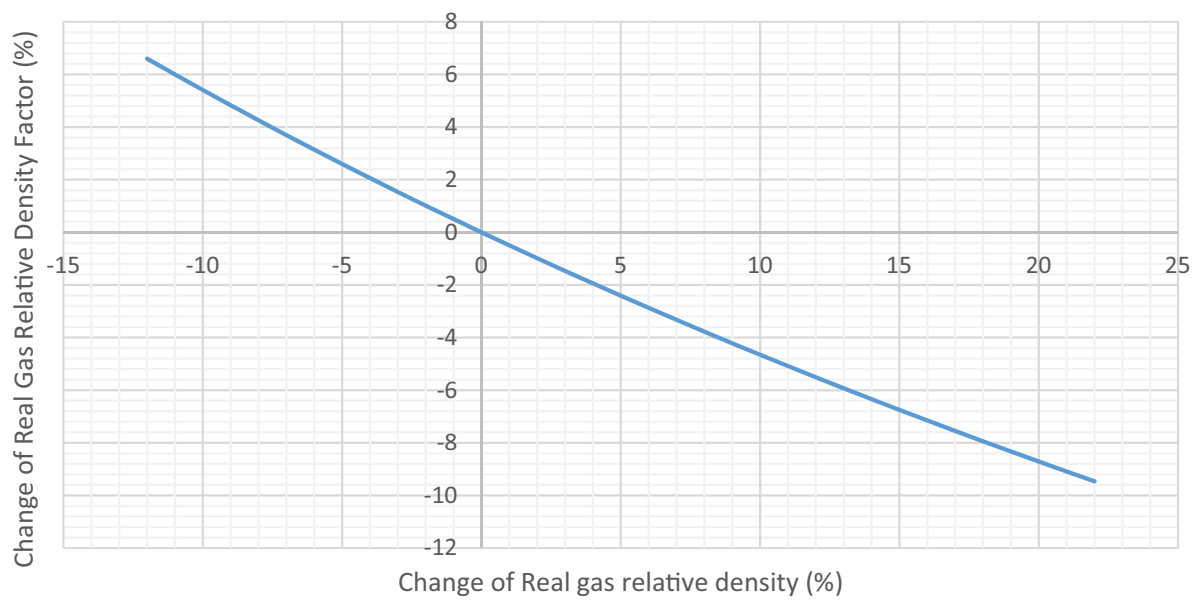


Fig. 36 Change of supercompressibility factor vs. change of real gas relative density

Fig. 37 Change of gas volume vs. change of Reynolds number
Change of Supercompressibility Factor vs. Change of Real gas relative density

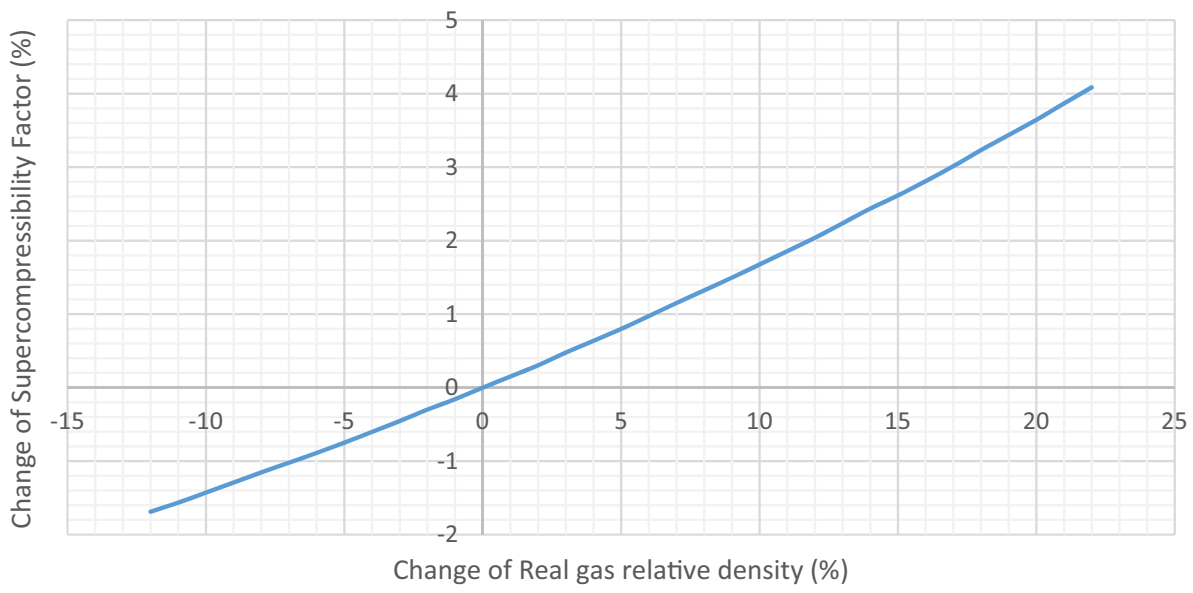

Change of Gas Volume vs Change of Reynolds Number

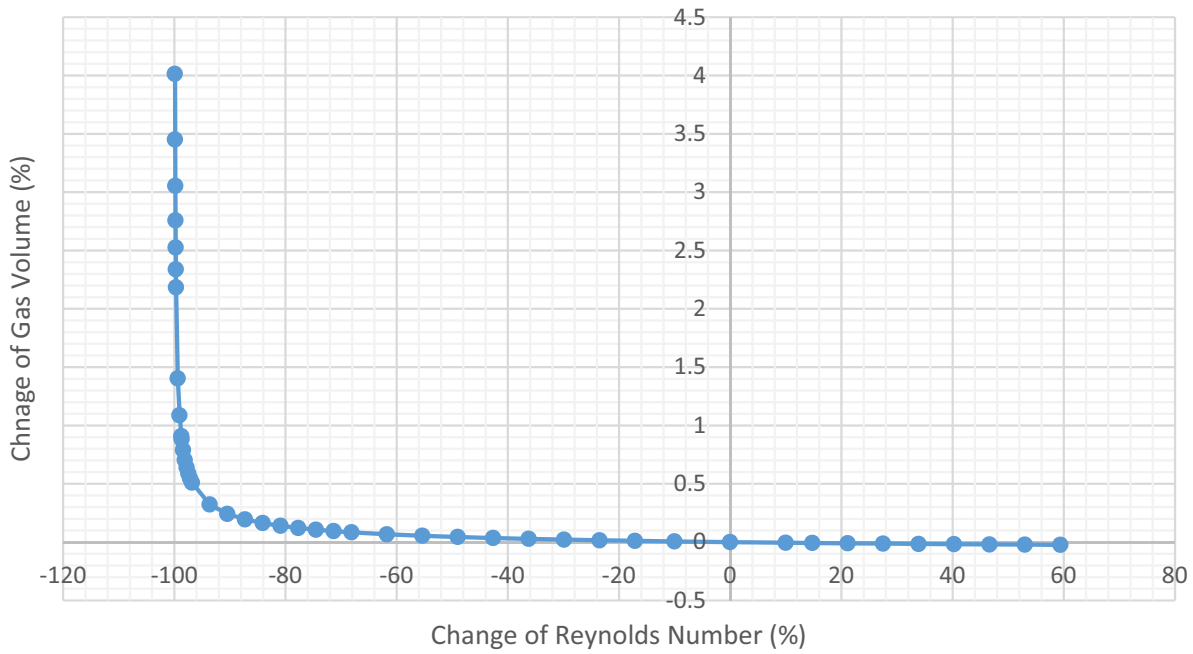


Fig. 38 Change of orifice calculation factor vs. change of Reynolds number

Fig. 39 Change of orifice slope factor vs. change of Reynolds number

Fig. 40 Change of coefficients of discharge vs. change of Reynolds number
Change of Orifice Calculation Factor vs. Change of Reynolds Number

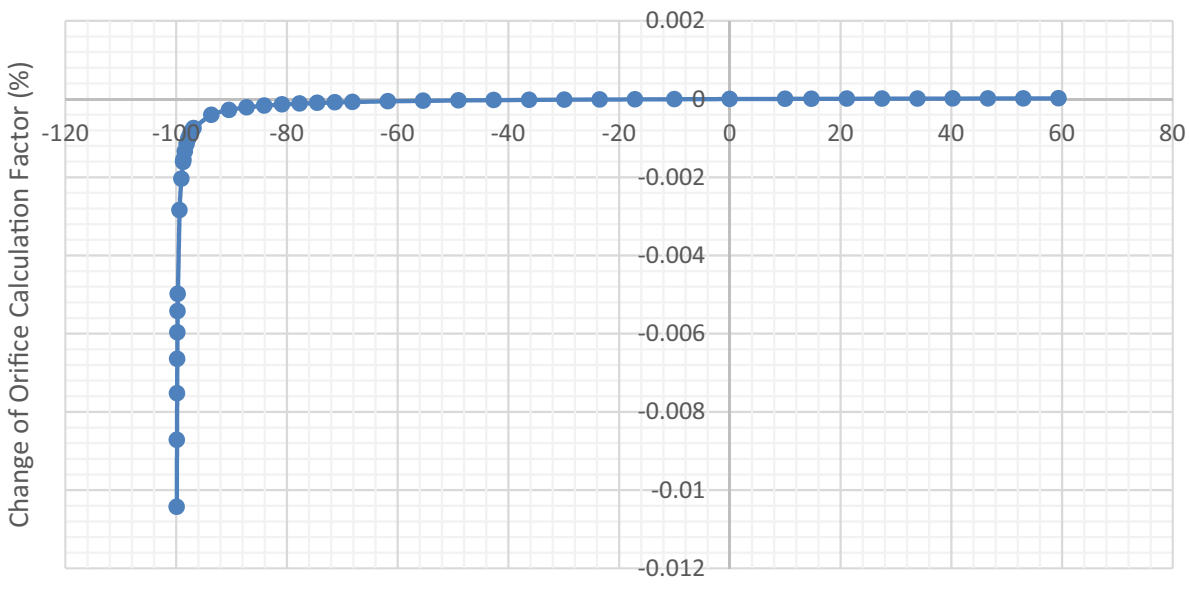

Change of Reynolds Number (\%)

Change of Orifice Slope Factor vs. Change of Reynolds Number

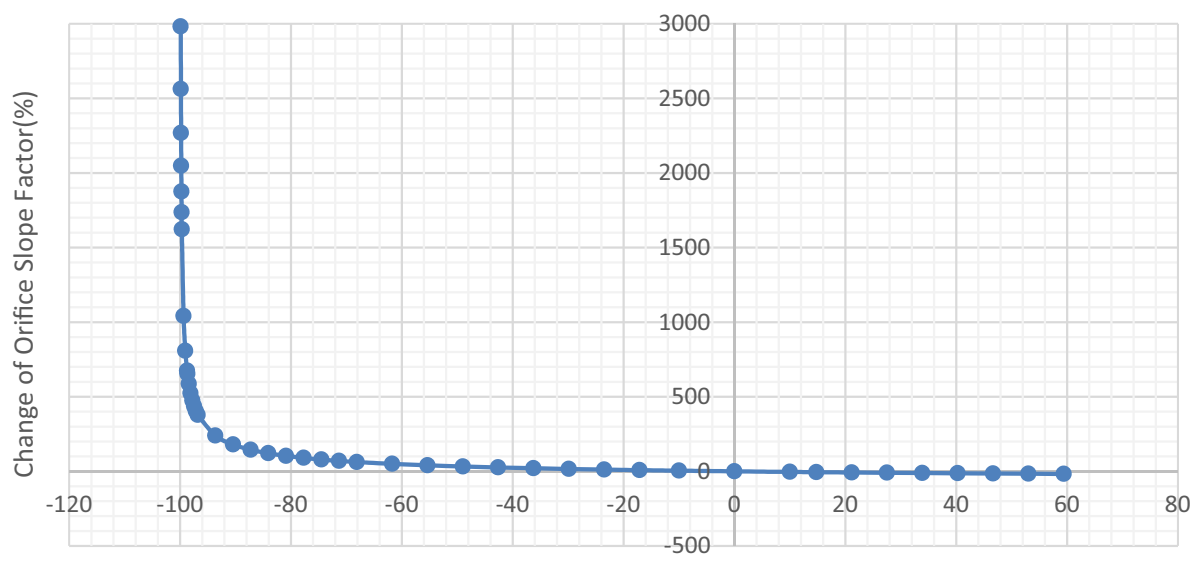

Change of Reynolds Number (\%)

Change of Coefficients of Discharge vs. Change of Reynolds Number

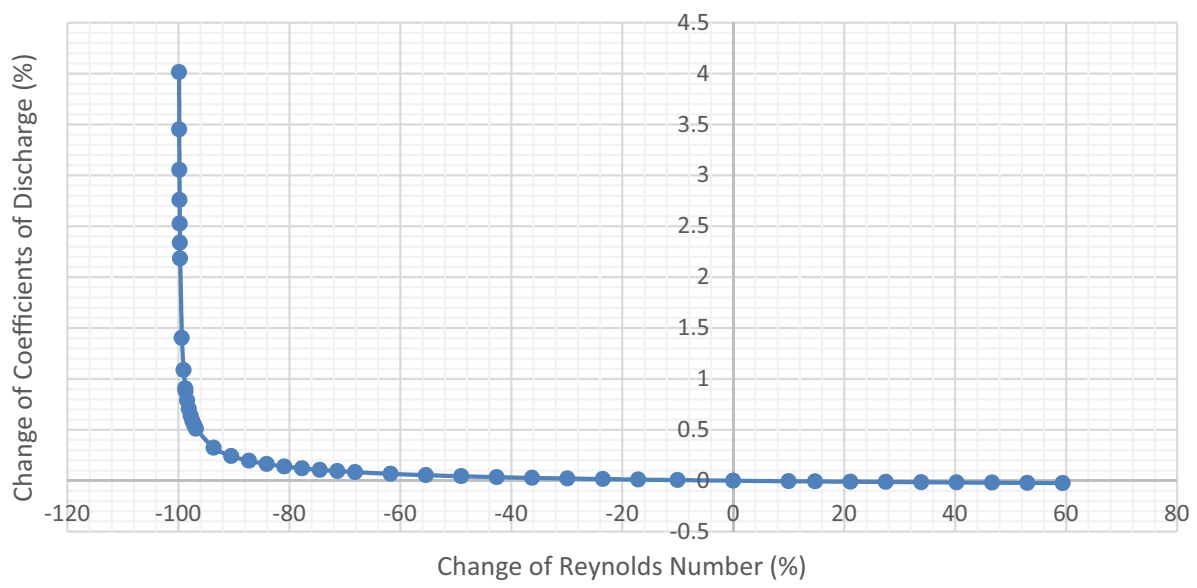


Funding There was no funding for conducting this research.

\section{Declarations}

Conflict of interest The authors declare that there is no conflict of interest that may results in bias in this research.

Open Access This article is licensed under a Creative Commons Attribution 4.0 International License, which permits use, sharing, adaptation, distribution and reproduction in any medium or format, as long as you give appropriate credit to the original author(s) and the source, provide a link to the Creative Commons licence, and indicate if changes were made. The images or other third party material in this article are included in the article's Creative Commons licence, unless indicated otherwise in a credit line to the material. If material is not included in the article's Creative Commons licence and your intended use is not permitted by statutory regulation or exceeds the permitted use, you will need to obtain permission directly from the copyright holder. To view a copy of this licence, visit http://creativecommons.org/licenses/by/4.0/.

\section{References}

American Gas Association, Report No. 1 (1930) Gas measurement manuals-part 1: general

American Gas Association, Report No. 3 (1955) Orifice metering of natural gas and other related hydrocarbon fluids, 1 st edn

American Gas Association, Report No. 3 (1985a) Orifice metering of natural gas and other related hydrocarbon fluids, 2nd edn

American Gas Association, Report No. 8 (1985b) Compressibility factors of natural gas and other related hydrocarbon gases, 1st edn

American Gas Association, Report No. 3 (1992) Orifice metering of natural gas and other related hydrocarbon fluids, 3rd edn

American Gas Association, Report No. 11 (2001) Coriolis flow measurement for natural gas applications. American Gas Association, Washington, D.C.

American Gas Association, Report No. 7 (2006) Measurement of natural gas by turbine meters, 2006 edn

American Gas Association, Report No. 3 (2012) Orifice metering of natural gas and other related hydrocarbon fluids, 4 th edn

American Petroleum Institute (2002) Manual of petroleum measurement standards chapter 5-metering, section 6-measurement of liquid hydrocarbons by Coriolis meters (API MPMS Chapter 5.6, R2008)

Anklin M et al (2006) Coriolis mass flowmeters: overview of the current state of the art and latest research. Flow Measure Instrum 17(6):317-323. doi:https://doi.org/10.1016/j.flowmeasinst.2006. 07.004

Baker RC (1991) Turbine and related flowmeters: I. industrial practice. Flow Meas Instrum 2(3):147-161. https://doi.org/10.1016/ 0955-5986(91)90027-o

Baker RC (2016) Flow measurement handbook: industrial designs, operating principles, performance, and applications, 2nd edn. Cambridge UP, Cambridge, UK

Bean HS (1935) Values of discharge coefficients of square-edged orifices: comparison of results obtained by tests using gases with those obtained by tests using water. Am Gas Assoc Monthly $17: 259$

Beitler SR (1935) "The flow of water through orifices" (Bulletin 89). Ohio State University, Columbus, Engineering Experiment Station

Benedict RP, Wyler JS, Brandt GB (1974) The effect of edge sharpness on the discharge coefficient of an orifice. Trans ASME J Eng Power (paper No 72-WA/FM-4)
Bobovnik G et al (2005) Coupled finite-volume/finite-element modelling of the straight-tube coriolis flowmeter. J Fluids Struct 20(6):785-800. https://doi.org/10.1016/j.jfluidstructs.2005.04.008

Bobovnik G et al (2013) Numerical analysis of installation effects in coriolis flowmeters: a case study of a short straight tube full-bore design. Flow Meas Instrum 34:142-150. https://doi.org/10.1016/j. flowmeasinst.2013.10.004

Bobovnik G et al (2015) Numerical analysis of installation effects in coriolis flowmeters: single and twin tube configurations. Flow Meas Instrum 44:71-78. https://doi.org/10.1016/j.flowmeasinst. 2014.10.001

Brain TJS, Reid J (1973) Measurement of orifice plate edge sharpness. Meas Control 6:377-384. https://doi.org/10.1109/10.1177/00202 9407300600904

Buckingham E (1932) Notes on the orifice meter: the expansion factor for gases. National Bureau Stand J Res 9(RP 459):61

Cheesewright $\mathrm{R}$ et al (2000) The identification of external factors which influence the calibration of Coriolis Massflow meters. Flow Meas Instrum 11(1):1-10. https://doi.org/10.1016/s09555986(99)00023-0

Crockett KA, Upp EL (1973) The measurement and effects of edge sharpness on the flow coefficients of standard orifices. Trans ASME J Fluids Eng 95(2):271-275

DeOtte RE, Morrison GL, Panak DL, Nail GH (1991) 3-D laser doppler anemometry measurements of the axisymmetric flow field near an orifice plate. Flow Meas Instrum 2(2):115-123

Dranchuk PM, Abou-Kassem H (1975) Calculation of Z factors for natural gases Using equations of state. J Can Pet Technol 14(03). https://doi.org/10.2118/75-03-03

Durst F, Wang AB (1989) Experimental and numerical investigations of the axisymmetric, turbulent pipe flow over a wall mounted thin obstacle

Durst F, Founti M, Wang AB (1988) Experimental investigation of the flow through an axisymmetric constriction. Turbulent shear flows, vol 6. Springer-Verlag, pp 338-350

Emerson (2017) Daniel orifice plates and plate sealing units. Daniel Measurement and Control, Inc., Houston, TX

Emerson R (2021a) Rosemount ${ }^{\mathrm{TM}}$ DP flow meters and primary elements. September

Emerson (2021b) Micro motion technical overview and specification summary. Micro Motion, Boulder, CO

Griffiths A, Newcombe J (1970) Large-volume gas measurement. In: 36th Autumn research meeting of the institution of gas engineers

Grimley TA (2002) Installation effects testing of Coriolis flow meters with natural gas. In: The fifth international symposium of fluid flow measurement. Arlington, VA, USA

Hodgson JL (1917) The commercial metering of air, gas and steam. Minutes Proc Inst Civ Eng CCIV 108-193

Jepson P, Chipchase R (1975) Effect of plate buckling on Orifice Meter Accuracy. J Mech Eng Sci 17(6):330-337. https://doi.org/10. 1243/JMES_JOUR_1975_017_047_02

Kolahi K et al (1994) Coriolis mass flow measurement of gas under normal conditions. Flow Meas Instrum 5(4):275-283. https://doi. org/10.1016/0955-5986(94)90031-0

Koudal O, Brunner M, Wenger A, Sorokin SV (1998) High frequency Coriolis meter performance under pulsating flow conditions. In: Proceedings of the 9th international conference on flow measurement. Sweden, Lund, pp 239-242

Kutin J et al (2006) Velocity profile effects in coriolis mass flowmeters: recent findings and open questions. Flow Meas Instrum 17(6):349-358. https://doi.org/10.1016/j.flowmeasinst.2006.07. 005

Li YT, Lee SY (1953) A fast-response true-mass-rate flowmeter. Trans ASME 75:835-841 
Li H, Zhang T, Zhang J (2013) Malfunction diagnosis of sludge deposition in standard orifice plate flowmeter. In: Proceedings of 2013 2nd International Conference on Measurement, Information and Control, pp. 1319-1323. https://doi.org/10.1109/MIC.2013.67582 02

Liu W et al (2015) Performance measurement analysis of various cone flow meters with various beta edge types and flow field parameters. Flow Meas Instrum 45:331-340. doi:https://doi.org/10. 1016/j.flowmeasinst.2015.07.005

McCrometer (2018) Proven flow measurement solutions for the oil and gas industry. McCrometer, Hemet, CA

McCrometer (2013) VH wafer style specification sheet. McCrometer, Hemet, CA

McCrometer (2013) Installation \& maintenance instructions V-cone. McCrometer

Miller RW (1979) The Stolz and ASME-AGA orifice equation compared to laboratory data. J Fluids Eng 101(4):483-490

Mole N et al (2008) An improved three-dimensional coupled fluidstructure model for coriolis flowmeters. J Fluids Struct 24(4):559 575. https://doi.org/10.1016/j.jfluidstructs.2007.10.004

Morrison GL et al (1990) The flow field inside an orifice flow meter. Chem Eng Prog 86(7):7580

Morrison GL, DeOtte RE, Beam EJ (1992b) Installation Effects upon Orifice Flowmeters. Flow Meas Instrum 3(2):8993. https://doi. org/10.1016/09555986(92)90005P

Morrison GL, DeOtte RE Jr, Nail GH, Panak DL (1993) Mean velocity and turbulence fields inside a $\beta=0.50$ orifice flowmeter. AIChE J 39:745-756

Morrison GL, Hauglie J, DeOtte RE (1995) Beta ratio, axisymmetric flow distortion and swirl effects upon orifice flow meters. Flow Meas Instrum 6(3):207216. https://doi.org/10.1016/09555986(95) 00009B

Morrison GL, DeOtte RE, Beam EJ (1992a) Installation effects upon orifice flow meters. In: 71st annual gas processors association convention. Anaheim, California

Morrow TB et al. (1991) Effects of orifice meter installation condition on orifice coefficient accuracy. In: SPE Gas Technology Symposium, 22 Jan. 1991, p. SPE-21509-MS. https://doi.org/10.2118/ 21509-MS

Nemitallah MA et al (2014) Solid particle erosion downstream of an orifice. J Fluids Eng 137(2). https://doi.org/10.1115/1.4028283

Norman RS, Mattingly GE, McFaddin SE (1989) The Decay of Swirl in Pipes, presented at 1989 International Gas Research Conference, Tokyo, Japan, November 6-9, 1989

O'banion, Micro Motion, Inc., Tom (2013) Coriolis: the direct approach to mass flow measurement. CEP Magazine

Ouazzane AK, Benhadj R (2002) Flow conditioners design and their effects in reducing flow metering errors. Sens Rev 22(3):223-231. https://doi.org/10.1108/02602280210433061

Pope JG, Wright JD (2014) Performance of coriolis meters in transient gas flows. Flow Meas Instrum 37:42-53. https://doi.org/10.1016/j. flowmeasinst.2014.02.003

Reader-Harris MJ (1994) The decay of swirl in a pipe. Int J Heat Fluid Flow 15(3):212-217. https://doi.org/10.1016/0142727X(94) 90040X

Reader-Harris MJ, Sattary JA (1990) The orifice plate discharge coefficient equation. Flow Meas Instrum 1(2):6776. https://doi.org/10. 1016/09555986(90)900312

Reader-Harris MJ, Sattary JA, Spearman EP (1995): "The Orifice Plate Discharge Coefficient Equation - further Work.” Flow Meas Instrum 6(2):101-114. https://doi.org/10.1016/09555986(94) 000010
Reader-Harris MJ (2015) Orifice plates and venturi tubes. Springer International Publishing, Cham. https://doi.org/10.1007/ 978-3-319-16880-7

Reader-Harris M, Barton N, Hodges D (2012) The effect of contaminated orifice plates on the discharge coefficient. Flow Meas Instrum 25:2-7. https://doi.org/10.1016/j.flowmeasinst.2011.11. 003

Sheikholeslami MZ, Patel BR (1988) Numerical modeling of flow through orifice meters. Topical Report, July 1986 August 1987, United States

Shen JJS (1991) Characterization of swirling flow and its effects on orifice metering. https://doi.org/10.2118/22865MS

Singh SN et al (2006) Effect of upstream flow disturbances on the performance characteristics of a V-cone flowmeter. Flow Meas Instrum 17(5):291-297. https://doi.org/10.1016/j.flowmeasinst. 2006.08.003

SmartMeasurement (2019) ALCM-MB micro-bend coriolis mass flowmeter model ALCM series. SmartMeasurement, Milwaukee, WI

ISO Standard 5167 (1980) Measurement of fluid flow by means of orifice plates, nozzles and venturi tubes inserted in circular crosssection conduits running full, ISO 5167-1980(E), Geneva

ISO Standard 5167-5 (2016) Measurement of fluid flow by means of pressure differential devices inserted in circular cross-section conduits running full-part 5: Cone Meters, ISO 5167-5:2016(E), Geneva

Shan F, Liu Z, Liu W, Tsuji Y (2016) Effects of the Orifice to Pipe Diameter Ratio on Orifice Flows. Chemical Engineering Science, vol. 152, pp. 497-506. https://doi.org/10.1016/j.ces.2016.06.050

Standing MB, Katz DL (1942) Density of Natural Gases. Trans AIME 146:140-149

Stappert K (2013) Fundamentals of coriolis meters Aga report no. 11

Stewart DG (2002) Performance of coriolis meters in gas flow. In: The fifth international symposium of fluid flow measurement (ISFFM)

Stolz J (1978) A universal equation for the calculation of discharge coefficient of orifice plates. Flow Measurement of Fluids, NorthHolland, Amsterdam

Szabo JL, Winarski CP, Hypnar PR (1992) A review of the V-cone meter for natural gas flows. Omae Calgary, Alberta

Tek-Trol (2021) Tek-Cor 1100A coriolis mass flow meter instruction manual, Tek-Trol, Crystal Lake, IL

Trifilieff O, Thomas W (2009) Black powder removal from transmission pipelines: diagnostics and solutions. PALL

Tsochatzidis NA (2008) Study addresses black powder's effects on metering equipment. Oil Gas J 106(12):56-58, 60-61

Upp EL (2016) Fundamentals of orifice meter measurement. Emerson Process Management. N.p

Wang T, Baker R (2014) Coriolis flowmeters: a review of developments over the past 20 years, and an assessment of the state of the art and likely future directions. Flow Meas Instrum 40:99-123. https:// doi.org/10.1016/j.flowmeasinst.2014.08.015

Weymouth TR (1912) Measurement of natural gas. Trans ASME 34:1091

Whetstone JR, Cleveland WG, Bateman BR, Sindt CF (1988) Measurements of coefficients of discharge for concentric, flange-tapped, square-edged orifice meters in natural gas over a Reynolds number range of 25,000-16,000,000. NIST Technical Note TN-1264. NIST, Washington D.C 